Caroline Furtado Noble

\title{
Mutações de resistência aos inibidores da polimerase em pacientes monoinfectados pelo vírus da Hepatite C e coinfectados HCV-HIV
}

Dissertação apresentada à Faculdade de Medicina da Universidade de São Paulo para obtenção do título de Mestre em Ciências.

Programa de Ciências em Gastroenterologia.

Orientador: Prof. Dr. Flair José Carrilho

São Paulo

2016 
Caroline Furtado Noble

\section{Mutações de resistência aos inibidores da polimerase em pacientes monoinfectados pelo vírus da Hepatite C e coinfectados HCV-HIV}

Dissertação apresentada à Faculdade de Medicina da Universidade de São Paulo para obtenção do título de Mestre em Ciências.

Programa de Ciências em Gastroenterologia.

Orientador: Prof. Dr. Flair José Carrilho

São Paulo

2016 


\section{Dados Internacionais de Catalogação na Publicação (CIP)}

Preparada pela Biblioteca da

Faculdade de Medicina da Universidade de São Paulo

๑)reprodução autorizada pelo autor

Noble, Caroline Furtado

Mutações de resistência aos inibidores da polimerase em pacientes monoinfectados pelo vírus de hepatite $\mathrm{C}$ e coinfectados $\mathrm{HCV}$-HIV I

Caroline Furtado Noble. -- São Paulo, 2016.

Dissertação(mestrado)--Faculdade de Medicina da Universidade de São Paulo.

Programa de Ciências em Gastroenterologia.

Orientador Flair José Carrilho.

Descritores: 1.Mutação 2.Vírus da hepatite C 3.Inibidores enzimáticos 4.Coinfecção 5.Infecções por HIV 6.Agentes antivirais 7.Resistência a medicamentos 8.Biologia molecular

USP/FM/DBD-125/16 


\section{AGRADECIMENTOS}

Aos meus pais Edna dos Reis Furtado e Stephen Noble Wright que me me formaram como cidadã e me proporcionaram toda a educação permitiu-me alcançar meus objetivos de maneira digna e honesta. Especialmente à minha querida mãe, obrigada por acreditar, me apoiar e deixar sonhar, sem a sua presença e amor eu jamais teria conseguido.

À toda minha família Furtado que acreditou no meu sucesso e esteve presente nos momentos mais difíceis deste percurso me apoiando e incentivando sempre: Jane Meire Angelini, Carlos Angelini, Amanda Angelini de Araújo, Vitor Angelini de Araújo, Felipe Angelini de Araújo, Julio César Furtado, Dinorá Furtado de Araujo e Alves de Araujo.

Aos meus amigos João Paulo Moreira e Marcelo Andreatta Corral. Eles compõe uma parte das conquistas que adquiri durante este aprendizado e que levarei para a vida toda. Amigos, muito obrigada.

Às minhas amigas e companheiras que me incentivaram nos momentos de resiliência não me deixando fraquejar e acreditaram que eu era capaz: Linda Simka, Aneta Czaja e Emily Cullum. Thank you girls, without you all I wouldn't have made it for sure. I believe we all have a special role in each others lives. And honestly I don't know what god was planning when he put you guys in my life, but he was wright and I'll be forever thankfull for that. Love you all." Agradeço especialmente à minha maior incentivadora Rafaela Martins. Obrigada amiga por estar ao meu lado em todas as horas da ultima etapa dessa árdua tarefa, pelas alegrias, puxadas de orelha, por aguentar meus prantos, colocar meus pés no chão e acima de tudo por acreditar que eu era capaz.

À Universidade de São Paulo, especialmente à Faculdade de Medicina da Universidade de São Paulo e ao Instituto de Biociências que me proporcionaram toda a formação acadêmica para a realização desta dissertação de Mestrado.

Ao Instituto de Medicina Tropical da USP e ao Departamento de Gastroenterologia da Faculdade de Medicina da USP que me proporcionaram toda a estrutura física e laboratorial para execução desta pesquisa.

À Fundação de Amparo à Pesquisa do Estado de São Paulo (FAPESP) e à Coordenação de Aperfeiçoamento de Pessoal de Nível Superior (CAPES) pelo apoio financeiro disponibilizados para a realização deste trabalho.

Aos pacientes participantes desta pesquisa. Obrigada pela participação e pela confiança. Um agradecimento especial e meus pesares àqueles que se foram antes mesmo da conclusão deste estudo. Não existem palavras que possam confortar família e amigos que perdem um ente querido para uma difícil batalha contra uma doença devastadora. Deixo aqui minha imensa gratidão e eterno agradecimento a todos os pacientes que fizeram deste estudo possível.

Ao Prof. Dr. Flair José Carrilho que me concebeu a oportunidade de realizar este estudo. Obrigada pela confiança. 


\section{AGRADECIMENTOS}

À Fernanda de Melo Malta que se dedicou arduamente para a realização deste estudo. Sua monitoria foi essencial para a realização de cada passo deste estudo e seus conselhos e ajuda foram fundamentais para a conclusão desta dissertação. Ela foi uma verdadeira orientadora.

À Michele Soares Gomes-Gouvêa que participou ativamente nas etapas cruciais a execução deste trabalho. Sem seus conselhos e conhecimentos específicos na área este trabalho não teria sido possível.

Ao Dr. João Renato Rebello Pinho que compartilhou seu conhecimento para desenvolvimento desta pesquisa

À Dra. Maria Cássia Jacintho Mendes Corrêa que me possibilitou participar de uma parte de sua pesquisa que se tornou tema da minha dissertação de Mestrado. Serei eternamente grata por sua confiança e por ter compartilhado conselhos valiosos para o desenvolvimento desta pesquisa.

Aos médicos que acompanham os pacientes neste estudo especialmente ao Dr. Gaspar Lisboa Neto que contribuiu de maneira valiosa para compilação e organização de todos os dados clínicos incluídos neste estudo.

À Equipe de biologia molecular do LATE-Hospital Albert Einstein pelos exames de confirmação de genotipagem e carga viral.

Aos meus amigos no laboratório Ariana Carolina Ferreira, Cris Nakle, Livia Botelho-Lima e Maiara Gottadi. Eles estiveram presentes durante todos os momentos bons e me auxiliaram nas horas difíceis.

Aos meus colegas de laboratório Karine Vieira Kaspareto, Ana Catharina Seixas Santos Nastri, Paola Lara Faria, Ketty Gleyzer de Oliveira e Max Diego Cruz Santos que sempre me apoiaram e torceram muito pelo meu sucesso.

Aos funcionários do laboratório Clarice Lemos, Fatima Dantas, Dirce Mary Correia Lima, que estiveram presentes em minha rotina. 


\section{EPÍGRAFE}

"A ciência nunca vesolve um problema sem criar pelo menos outros dey". (George Bernard Shaw) 


\title{
SUMÁRIO
}

\author{
LISTA DE FIGURAS \\ LISTA DE TABELAS \\ RESUMO \\ SUMMARY
}

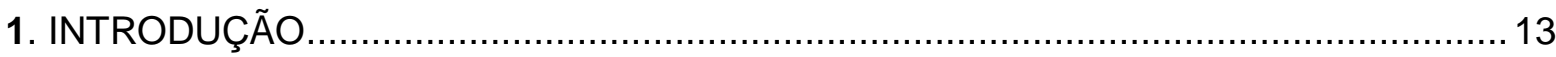

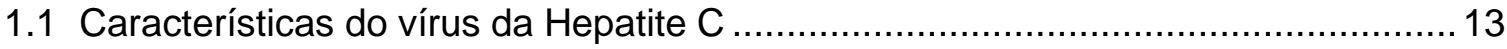

1.2 Diversidade viral e classificação dos genótipos do HCV ........................................ 14

1.3 Epidemiologia da Hepatite $\mathrm{C}$.................................................................... 16

1.4 História natural da Hepatite $\mathrm{C}$.................................................................. 19

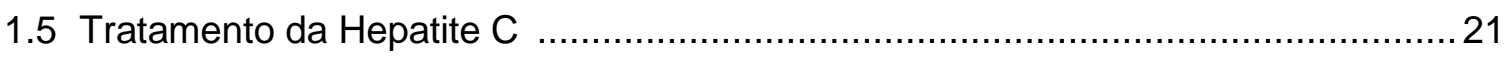

1.5.1 Mecanismos de ação dos inibidores de polimerase (NS5B) e variantes

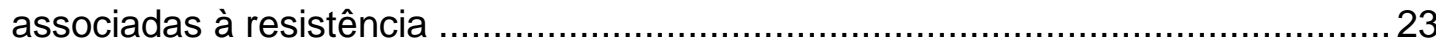

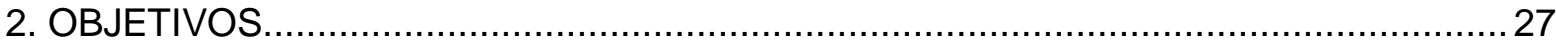

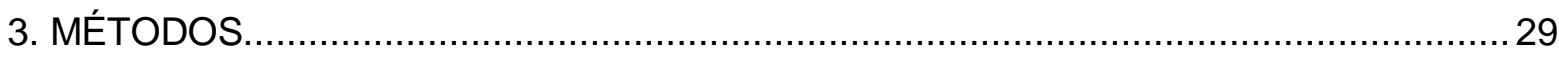

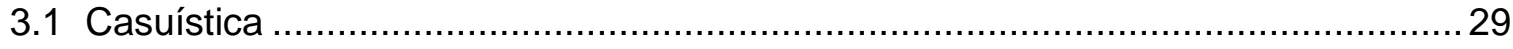

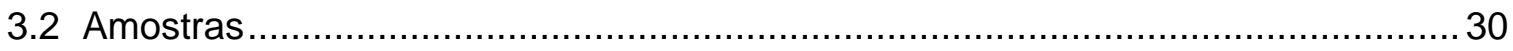

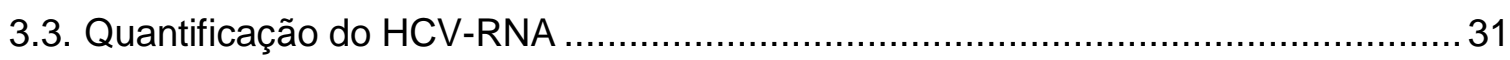

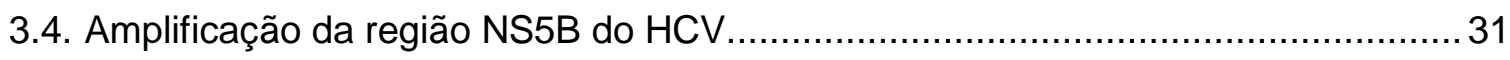

3.5. Identificação e quantificação dos produtos de PCR ............................................ 32

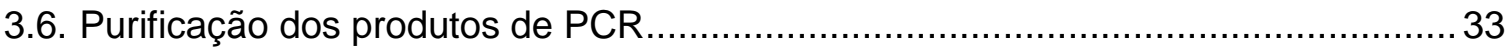

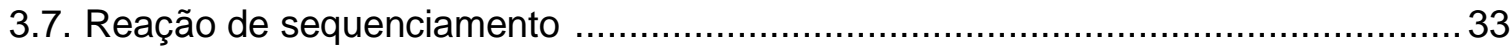

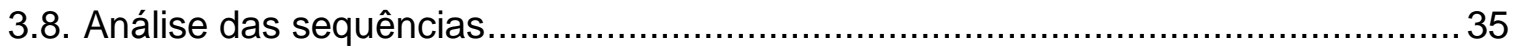

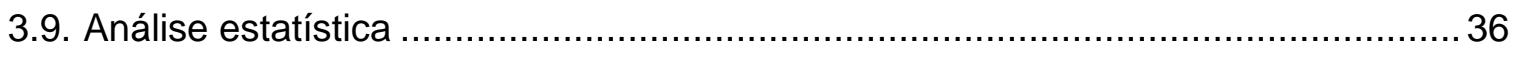

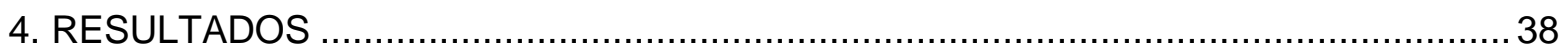

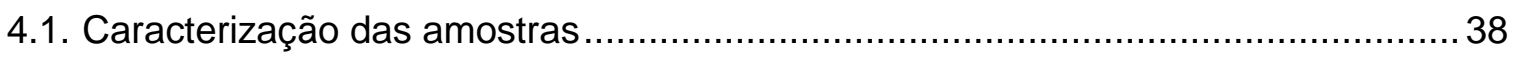

4.2. Análise da frequência das mutações presentes na região NS5B do HCV ............. 40

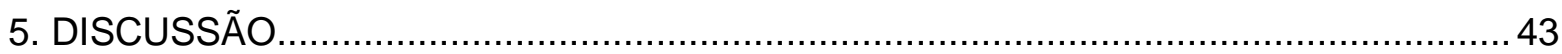

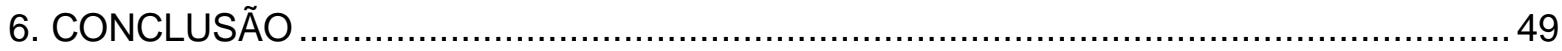

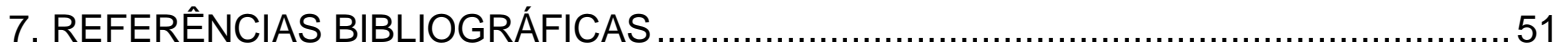
Apêndices 
Figura 1 - Organização do genoma do HCV, processamento da poliproteína e topologia das proteínas virais

Figura 2 - Diversidade Genética dos vírus da Hepatite C, Hepatite B e o vírus da HIV

Figura 3 - Prevalência estimada da infecção pelo HCV e a distribuição mundial dos genótipos e subtipos do HCV

Figura 4 - Prevalência de base populacional da infecção pelo HCV no Brasil

Figura 5 - História natural da Hepatite C

Figura 6 - Estrutura cristalográfica da RNA-polimerase RNAdependente (NS5B do HCV). Domínios Fingers (vermelho) e Thumb (azul) envolvendo o sítio ativo dentro do domínio Palm (verde)

Figura 7 - Fluxograma das etapas de processamento das amostras e seus respectivos resultados 
Tabela 1 - Proteínas do HCV e suas respectivas funções

Tabela 2 - Sequência de primers utilizados para a amplificação da região NS5B do HCV

Tabela 3 - Substituições na NS5B associadas à resistência ao tratamento com inibidores de polimerase

Tabela 4 - Antiretrovirais em uso por pacientes coinfectados (HCV-HIV)

Tabela 5 - Mutações encontradas na região NS5B do HCV 


\section{RESUMO}

Noble CF. Mutações de resistência aos inibidores da polimerase em pacientes monoinfectados pelo vírus da Hepatite $C$ e coinfectados HCV-HIV [dissertação]. São Paulo: Faculdade de Medicina, Universidade de São Paulo; 2016. 65p

Nos últimos anos o tratamento da infecção crônica pelo HCV passou por importantes mudanças. Recentes avanços em biologia molecular proporcionaram o melhor conhecimento sobre a estrutura molecular do HCV e permitiram o desenvolvimento de moléculas que tem como alvo proteínas específicas integrantes do ciclo replicativo do vírus, denominados agentes antivirais de ação direta (DAAs). No Brasil, atualmente, os DAAs aprovados para o tratamento da Hepatite C são: Simeprevir (2 $2^{\underline{a}}$ geração de inibidor de protease), Daclatasvir (inibidor de NS5A) e o Sofosbuvir (inibidor análogo nucleotídeo de polimerase). A combinação dessas diferentes classes de DAAs permite maior eficácia no tratamento do $\mathrm{HCV}$, reduz a duração do tratamento e o risco da emergência de resistência. Ao mesmo tempo em que o desenvolvimento de DAAs promete melhorar a chance de sucesso do tratamento dos pacientes crônicos infectados pelo HCV, a emergência de variantes associadas à resistência representa um grande desafio ao sucesso da terapia antiviral atualmente proposta e informações sobre a presença dessas mutações ainda são escassas. Este estudo tem como objetivo o mapeamento de variantes associadas à resistência (RAVs) primárias aos inibidores da polimerase (NS5B) do HCV em pacientes monoinfectados (HCV) e em pacientes coinfectados (HCV/HIV). Para tal, o rastreamento de substituições de aminoácidos foi realizado entre as posições 159 e 495 da proteína NS5B do HCV nas sequências de 244 pacientes infectados pelo HCV1: 133 monoinfectados [1b $(n=93) ; 1 a(n=40)$ ] e 111 coinfectados [1a $(n=93) ; 1 b$ $(n=18)]$. A ocorrência natural de RAVs nos resíduos S282, L320 e P495 não foi observada nas sequências analisadas neste estudo. As RAVs encontradas no grupo de monoinfectados foram: L159F $(16,1 \%-1 b)$, C316N $(16,3 \%-1 b)$ e A421V (21,4\% - 1a; 3,2 - 1b) ; e no grupo de coinfectados foram: C316N $(7,1 \%$ - 1b), V321A (1,6\% - 1a), M414V (1,3\% - 1a); A421V (23,7\% - 1a; $6,3 \%-1 b)$, A421G (1,3\% - 1a); Y448H (1,3\% - 1a). Entre os pacientes monoinfectados, a região NS5B do HCV-1a apresentou menor número de variantes associadas à resistência (RAVs) quando comparada ao subtipo 1b, ao contrário do observado nos coinfectados. A variante $\mathrm{C} 316 \mathrm{~N}$ foi a única que ocorreu em combinação com outras variantes. Houve a ocorrência concomitante das variantes L159F e C316N em 8 pacientes monoinfectados pelo HCV-1b (8/56; $14,3 \%$ ). Entre os coinfectados, foi observada a ocorrência concomitante das variantes $\mathrm{C} 316 \mathrm{~N}$ e A421V em apenas 1 paciente infectado pelo HCV-1b (1/14; $7,1 \%$ ). A presença de RAVs foi detectada nas duas populações estudadas neste estudo. Contudo, outros estudos são necessários para que se possa avaliar o real impacto dessas mutacões na resposta ao tratamento.

Descritores: mutação, vírus da hepatite $\mathrm{C}$, inibidores enzimáticos, coinfecção, infecção por HIV, agentes antivirais, resistência a medicamentos, biologia molecular. 


\section{SUMMARY}

Noble CF. Resistance mutations associated to polymerase inhibitors in HCV monoinfected and HCV-HIV co-infected patients [dissertation]. São Paulo: "Faculdade de Medicina, Universidade de São Paulo"; 2016. 65p

The treatment of chronic HCV infection has undergone important changes recently. Advances in molecular biology provided a better knowledge of the HCV molecular structure and allowed the development of molecules which target specific proteins that have important roles in the viral replicative cycle, known as direct action antiviral agents (DAAs). In Brazil, DAAs approved for treating hepatitis $C$ are Simeprevir (2nd generation protease inhibitor), Daclatasvir (NS5A inhibitor) and sofosbuvir (nucleotide analogue NS5B polymerase inhibitor). The combination of these different DAAs classes leads to a greater efficacy in the treatment of HCV, reducing its duration and the risk of resistance associated variants (RAVs) emergence. DAAs increase the chance of successful treatment of HCV chronic infected patients. RAVs emergence represents a major challenge to the success of antiviral therapy. Nevertheless, data about the presence of these mutations are still scarce. The aim of this study was to verify the presence of primary RAVs associated to HCV polymerase inhibitors primary resistance in monoinfected $(\mathrm{HCV})$ and coinfected (HCV / HIV) patients. For this purpose, amino acid substitutions identification was conducted between positions 159 and 495 of the HCV NS5B protein in the sequences of 244 patients with HCV-1: 133 monoinfected [1a $(n=40) ; 1 b$ $(n=93)$ ] and 111 coinfected [1a $(n=93) ; 1 b(n=18)]$. Naturally occurring RAV in S282, L320 and P495 residues were not observed among the sequences analyzed in this study. RAVs found in monoinfected patients were L159F (16.1\% - 1b), C316N (16.3\% - 1b) and A421V (21.4\% - 1a; 3.2\% - 1b); while in co-infected group, the following RAVs were identified: C316N $(7.1 \%-1 b)$, V321A (1.6\% - 1a), M414V (1.3\% - 1a); A421V (23.7\% - 1a; 6.3\% - 1b), A421G $(1.3 \%-1 \mathrm{a}) ; \mathrm{Y} 448 \mathrm{H}(1.3 \%-1 \mathrm{a})$. Among monoinfected patients, HCV-1a NS5B region showed fewer RAVs when compared to HCV-1b, conversely to what was observed in HIV coinfected patients. Variant C316N occurred in combination with other ones: there was the simultaneous occurrence of L159F and C316N variants $8 / 56$ (14.3\%) $8 \mathrm{HCV}$-1b monoinfected patients Among the coinfected patients, it was observed concomitant occurrence of C316N and A421V variant in only $1 / 14(7.1 \%) \mathrm{HCV}-1 \mathrm{~b}$ infected patient. RAVs were detected in both HCV and HCV/HIV infected populations in this study. Further studies are required to assess the real impact of these changes in response to treatment.

Descriptors: mutation, enzyme inhibitor, coinfection, HIV infection, antiretrovirus agent, drug resistence, molecular biology 
Introdução 


\section{INTRODUÇÃO}

\subsection{Características do vírus da Hepatite C}

O vírus da hepatite $\mathrm{C}(\mathrm{HCV})$ pertence ao gênero Hepacivirus da família Flaviviridae [1], é um vírus RNA de fita simples, com polaridade positiva que possui envelope e seu genoma tem aproximadamente 9.600 nucleotídeos. [2] Estes estão organizados numa região aberta de leitura (ORF - open reading frame) que codifica uma poliproteína de aproximadamente 3.000 aminoácidos que será clivada e dará origem às proteínas estruturais (core, E1 e E2) e não estruturais (p7, NS2 a NS5B) (Figura 1). [3] Nos extremos dessa ORF encontram-se regiões não codificantes: 5'UTR e $3^{\prime}$ UTR, que têm uma importante função na regulação da ativação e replicação viral. $[4,5]$

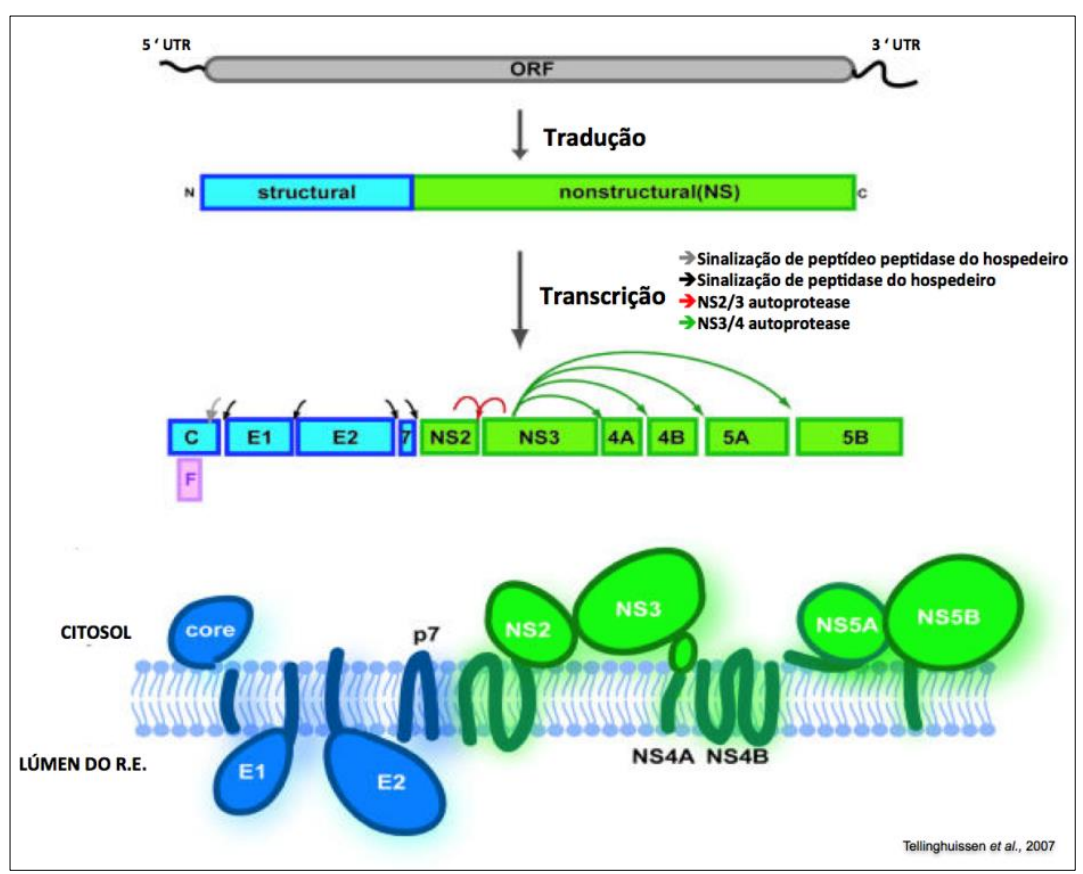

Figura 1 - Organização do genoma do HCV, processamento da poliproteína e topologia das proteínas virais. 
As funções das proteínas estruturais e não-estruturais do HCV estão resumidas na Tabela 1.

Tabela 1 - Proteínas do HCV e suas respectivas funções

\begin{tabular}{ll}
\hline \multicolumn{1}{c}{ Proteína } & \multicolumn{1}{c}{ Função } \\
\hline Core & $\begin{array}{l}\text { Proteína formadora do capsídeo. Funções de regulação da tradução e replicação } \\
\text { do RNA viral e montagem de particulas. }\end{array}$ \\
F-Proteína & Desconhecida \\
Glicoproteína 1 do envelope (E1) & $\begin{array}{l}\text { Glicoproteína transmembrana do envelope viral. Adsorção e endocitose mediada } \\
\text { por receptor. }\end{array}$ \\
Glicoproteína 2 do envelope (E2) & $\begin{array}{l}\text { Glicoproteína transmembrana do envelope viral. Adsorção e endocitose mediada } \\
\text { por receptor. }\end{array}$ \\
p7 & $\begin{array}{l}\text { Forma um canal iônico no retículo endoplasmático. Essencial na formação de } \\
\text { partículas virais infecciosas. }\end{array}$ \\
NS2 & $\begin{array}{l}\text { Porção da protease NS2-3, que catalisa a clivagem da poliproteína precursora } \\
\text { entre NS2 e NS3 }\end{array}$ \\
NS3 & Atividade ATPase / helicase, clivagem das proteínas não estruturais. \\
Crucial na replicação do HCV. Induz a formação da rede membranosa no RE \\
durante a replicação do RNA-HCV. \\
Cofator da protease NS3-NS4A. \\
FS4B
\end{tabular}

FONTE: Mauss et al., 2013 (Adaptado)

\subsection{Diversidade viral e classificação dos genótipos do HCV}

A grande diversidade genômica do HCV é representada por sete genótipos filogeneticamente distintos, que diferem de 30 a $35 \%$ entre si. A figura 2 mostra a elevada diversidade genética do HCV quando comparado à diversidade do vírus da imunodeficiência humana (HIV do inglês, human immunodeficiency syndrome) e do vírus da Hepatite B (HBV). [6] 


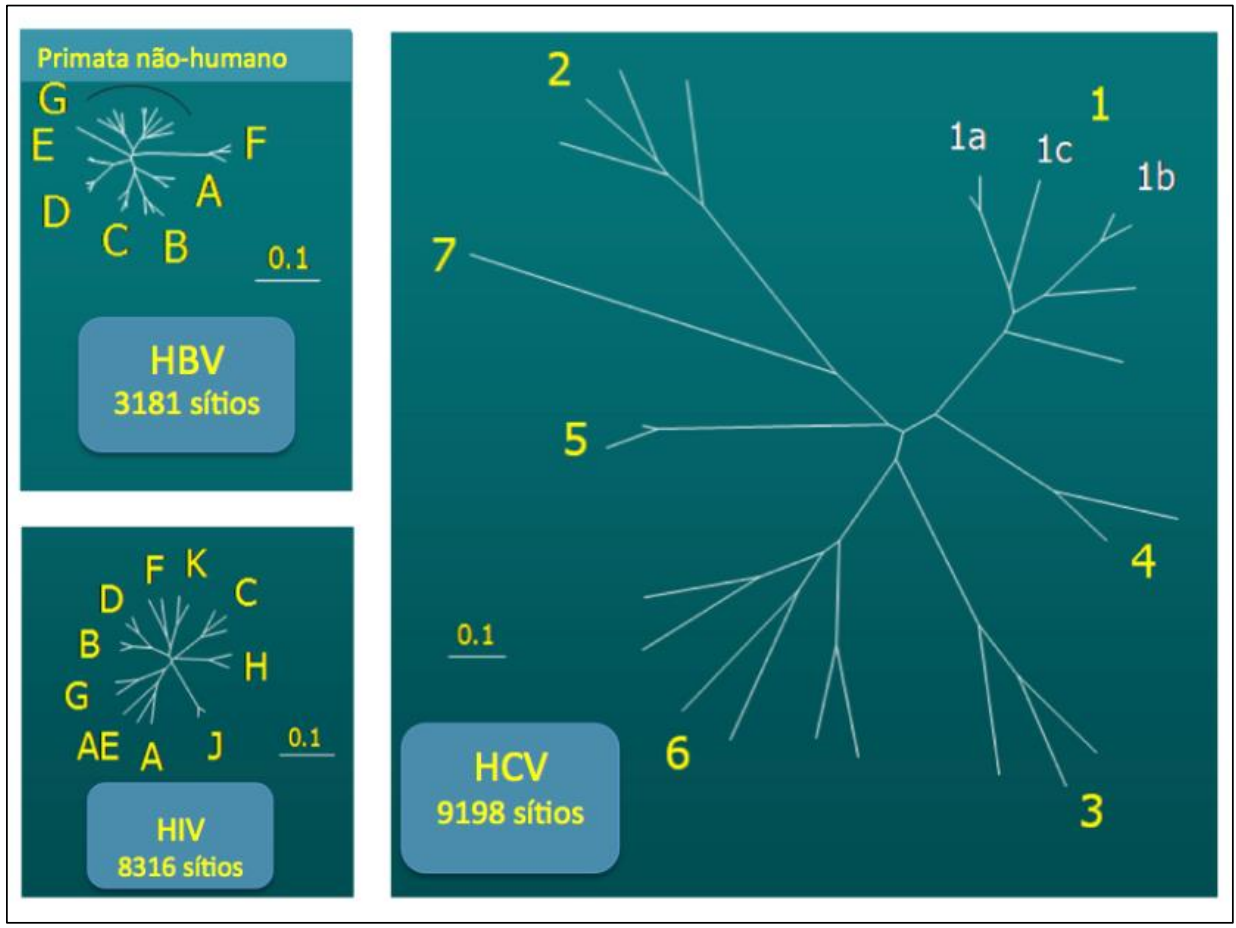

Figura 2 - Diversidade Genética dos vírus da Hepatite C, Hepatite B e o vírus da HIV.

A variabilidade genética do HCV está associada à baixa fidelidade da enzima RNA polimerase RNA dependente e à alta taxa de replicação viral, a qual facilita a adaptação do vírus ao hospedeiro. Esta variabilidade genética ocorre devido a uma taxa de mutação espontânea de cerca de 1,5 a $2 \times 10^{-3}$ substituições de nucleotídeos por sítio por ano [7, 8], que se faz mais evidente nos segmentos genéticos que codificam as proteínas E1, E2 e NS1. Este fato contrasta com o alto nível de conservação da região 5 `UTR. [9]

Estudos demonstram que os genótipos 1, 2 e 3 possuem distribuição mundial, já os genótipos 4 a 7 apresentam uma dispersão em áreas mais restritas. [10] O genótipo 4 é muito prevalente no Oriente Médio e na África Central. Em um estudo recente, uma alta taxa desse genótipo também foi relatada na Europa Meridional. O genótipo 5 é orginalmente muito prevalente 
na África do Sul, seguido pela Bélgica. No sudeste Asiático encontramos altas taxas de prevalência para o genótipo 6 . 0 genótipo 7 , recentemente descrito, parece ter sido originário da África Central. [11]

Entre os genótipos foram reportados mais de 100 subtipos, os quais se diferenciam entre si de 20 até $25 \%$ no seu genoma. [4, 7] Os subtipos são identificados pelas letras do alfabeto ( $a, b, c$ etc...). Nesta Classificação os subtipos 1a, 1b, 2c e 3a são os de maior prevalência global, sendo representados em todos os continentes do mundo. [8] Os subtipos $1 \mathrm{~b}, 2 \mathrm{a}, 2 \mathrm{~b}$ são mais prevalentes em grupos pertencentes a populações com idade mais avançada e estão em sua maioria ligados a transfusão de sangue.

\subsection{Epidemiologia da infecção pelo HCV}

O principal mecanismo de transmissão dessa infecção é parenteral, destacando-se as transfusões de sangue e seus derivados e o uso de drogas endovenosas ilícitas. Outros fatores de risco para essa infecção são a transmissão perinatal, a exposição a sangue ou secreções contaminadas em clínicas e hospitais, o contato com familiares e por via sexual. [12]

A Organização Mundial da Saúde (OMS) estima que cerca de 130 a 170 milhões de pessoas no mundo estejam infectadas pelo HCV, isso corresponde aproximadamente a $3 \%$ da população mundial. [2,13,14] O HCV é endêmico em vários países e se tornou motivo de preocupação crescente para a sociedade e seus sistemas de saúde. [15]

De acordo com informações disponíveis em seus relatórios periódicos, a OMS revela que esses números refletem os dados disponíveis em literatura relativos à cerca de 130 países. A maior prevalência do HCV foi relatada no 
Egito, atingindo mais de $10 \%$ da população geral, embora em números absolutos a China possua o maior número de infectados, cerca de 29,8 milhões de pessoas. [15] Ainda de acordo com a OMS, não existem dados sobre a prevalência dessa infecção em cerca de 60 outros países de forma que sua estimativa é parcial e sujeita a possíveis erros.

A Figura 3 mostra a distribuição global dos subtipos do HCV e suas respectivas taxas de prevalência mundial por país observado. Alguns países apresentam baixa prevalência dessa infecção $(<1 \%)$ como, por exemplo, Alemanha, Canadá, França, Bélgica, Noruega, Suécia, Reino Unido, Finlândia, Turquia, Venezuela e Chile. Outros apresentam prevalência um pouco mais elevada $(1,0-1,9 \%)$, como os Estados Unidos da América, Portugal, Polônia, Síria, Japão, China, Austrália, Brasil e Argentina. Finalmente, alguns países do mundo, como Egito, Paquistão e Itália apresentam prevalências ainda mais elevadas $(>2,9 \%)$. [15]

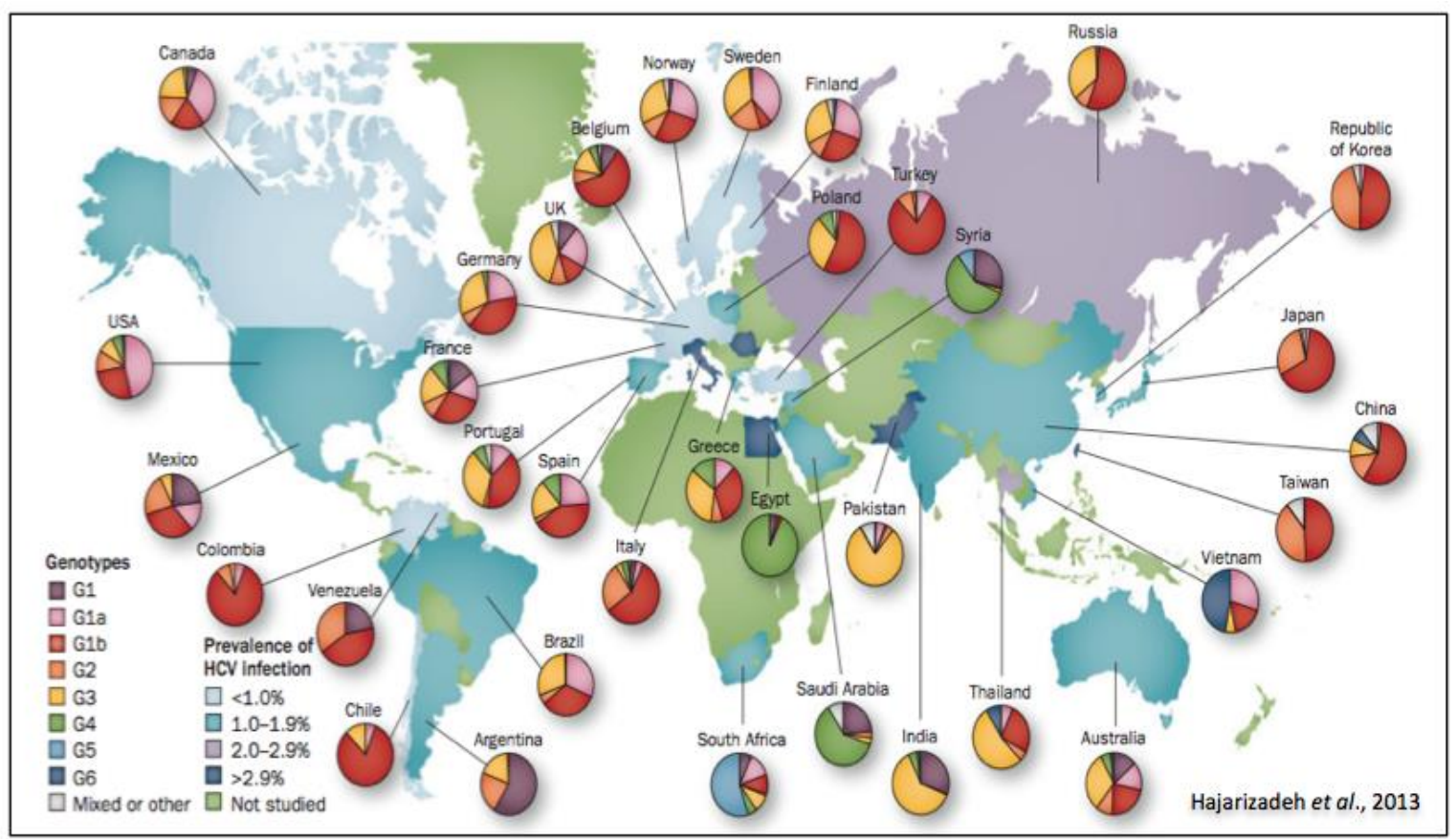

Figura 3 - Prevalência estimada da infecção pelo HCV e a distribuição mundial dos genótipos e subtipos do HCV. 
No Brasil, a maioria dos estudos avalia a prevalência dessa infecção em doadores de sangue ou outros grupos populacionais específicos, com resultados que variam nas diferentes regiões do Brasil. Um estudo de base populacional realizado no município de São Paulo identificou prevalência de $1,42 \%($ Anti-HCV +) entre as pessoas analisadas. [16]

Em um estudo soro epidemiológico realizado em diversas capitais brasileiras revelou uma prevalência da presença de marcador sorológico AntiHCV em $0,32 \%$ a 2,9\%, dos pacientes analisados, dependendo da região brasileira analisada e da faixa etária envolvida (Figura 4). [17]

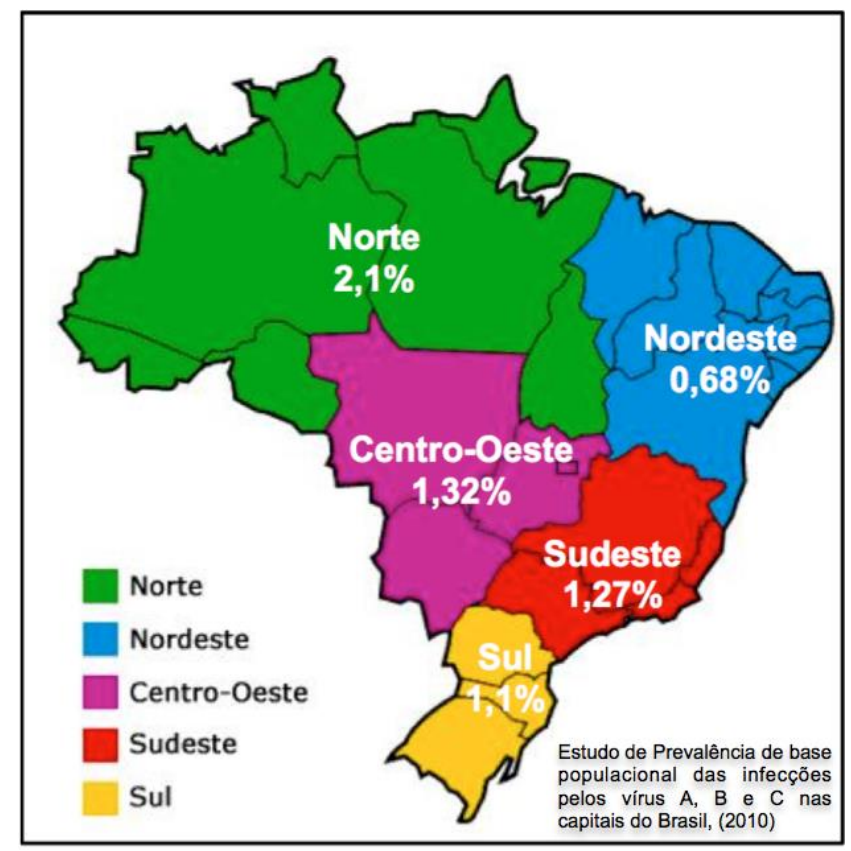

Figura 4 - Prevalência de base populacional da infecção pelo HCV no Brasil

O HCV e o HIV são transmitidos principalmente pelo contato com sangue contaminado, ou seja, pela via parenteral. Por compartilharem essa importante via de transmissão, a infecção pelo HCV é frequente entre os pacientes portadores do HIV. Nos Estados Unidos da América, Europa e 
Austrália, avalia-se que a prevalência ocorra em $25-30 \%$ dos pacientes infectados pelo HIV. [18, 19]

A prevalência da coinfeccao pelo HCV varia dependendo das vias de transmissão do HIV, sendo mais baixa em indivíduos com elevado risco de exposição sexual ( $1 \%$ a $12 \%$ dos heterossexuais e $9 \%$ a $27 \%$ dos homens que possuem relação sexual com outros homens - MSM) e mais alta entre usuários de droga que compartilham seringas e agulhas (70\% a 95\%). [20-23] Durante a ultima década, a incidência de novas infecções pelo HCV tem diminuído drasticamente, todavia, casos de hepatite $C$ aguda continuam a incidir em alguns cenários populacionais, bem como usuários de drogas injetáveis, MSM, indivíduos com comportamento sexual de risco e procedimentos ligados a serviços de saúde. [24, 25] Consequentemente, tem sido reportado a emergência de endemias de infecção aguda pelo HCV em portadores de HIV, principalmente entre MSM, na Europa, Australia e Estados Unidos. [24],

No Brasil, as taxas de coinfecção do HCV/HIV variam de acordo com a distribuição geográfica e de fatores de risco (tipo de exposição para aquisição da doença). Diferentes estudos identificaram a presença de Anti-HCV entre os portadores do HIV e entre doadores de sangue e as taxas variam de 4,1 a 53,8\%. [26-28]

\subsection{História natural da Hepatite C}

A evolução da infecção pelo vírus da hepatite C pode ser bastante variável, pois a progressão da doença esta diretamente relacionada a fatores virais, tais como, genótipo, carga viral, e também a características do indivíduo 
como o tempo de infecção, idade, sexo, coinfecção pelo HIV e HBV. Estudos mostram que em $20 \%$ a $50 \%$ dos indivíduos infectados pelo HCV, o sistema imune consegue eliminar o vírus resolvendo a infecção na fase aguda, mas a maioria das pessoas desenvolve uma infecção crônica que, ao longo dos anos, pode progredir para uma doença grave com desenvolvimento de cirrose e em alguns casos poderão evoluir para carcinoma hepatocelular (Figura 5). [15, 2931]

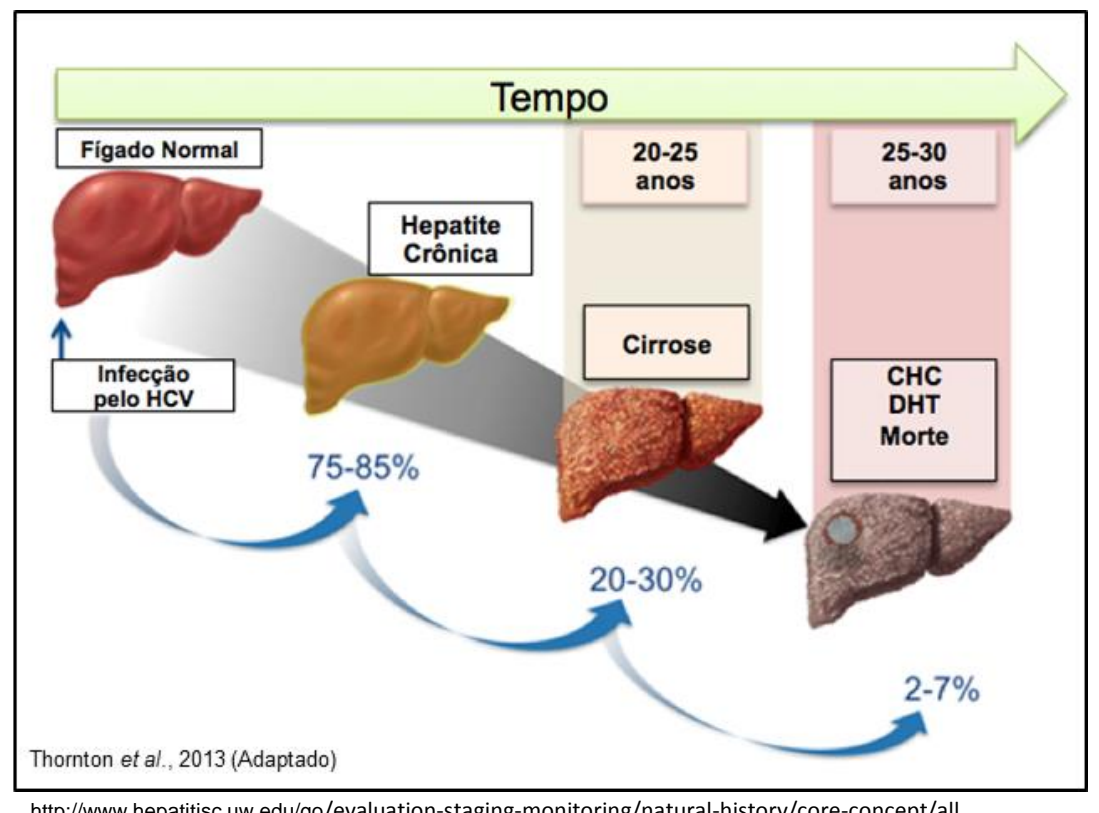

Figura 5 - História natural da Hepatite C. CHC - carcinoma hepatocelular; DHT - doença hepática terminal

A coinfecção com outros vírus pode exercer uma grande importância nesse cenário, como por exemplo, a coinfecção com HIV. A presença do HIV altera a evolução da hepatite C levando ao aumento da persistência viral apos a infecção aguda, elevação da viremia e acentuada progressão para cirrose hepática, assim como o surgimento de hepatocarcinoma, tais fatores 
determinam um impacto negativo na evolução da própria infecção pelo HIV. $[22,23,32,33]$

\subsection{Tratamento da Hepatite C}

Nos últimos anos o tratamento da infecção crônica pelo HCV passou por importantes mudanças. Até 2011, o tratamento era baseado na combinação de interferon alfa peguilado (PegIFNa) e ribavirina (RBV), este tratamento oferecia uma chance de resposta virológica sustentada de aproximadamente $40 \%-50 \%$ em indivíduos infectados pelo HCV genótipo 1 e de $60 \%-80 \%$ em indivíduos infectados pelos genótipos 2 e 3. [34, 35]

Recentes avanços em biologia molecular proporcionaram o melhor conhecimento sobre a estrutura molecular do $\mathrm{HCV}$, assim como, o estabelecimento de culturas celulares e sistema de replicação robusto permitiram o desenvolvimento de moléculas que tem como alvo proteínas específicas integrantes do ciclo replicativo do vírus, denominados antivirais de ação direta (DAAs - do inglês, direct acting antivirals). Os DAAs têm como alvo as proteínas não estruturais do HCV: a protease NS3/4A, a proteína NS5A e a RNA-polimerase RNA-dependente (RdRp) codificada pela região NS5B do genoma. [36]

Em 2011, dois inibidores de protease (PIs) o Boceprevir e o Telaprevir foram aprovados para o tratamento de pacientes infectados pelo genótipo 1 do HCV (GT-1). Esses medicamentos, associados à terapia com Peg-Interferon e Ribavirina (PR), aumentam a chance de cura em pacientes virgens de tratamento em 30\%. [37-40]. Contudo, devido à baixa eficácia antiviral e ao 
rápido desenvolvimento de resistência (devido à baixa barreira genética), esses dois medicamentos só puderam ser utilizados em combinação com interferon alfa peguilado e ribavirina (terapia tripla).

Entre 2014 e 2015, novos DAAs associados a elevadas taxas de resposta virológica sustentada foram aprovados para o tratamento da Hepatite C em esquemas livres de Interferon. Três classes de DAAs estão aprovadas: inibidores da protease (NS3), inibidores de NS5A, inibidores da polimerase (NS5B): não-nucleosídeos e análogos núcleotídeos. [41]

No Brasil, atualmente, os DAAs aprovados para o tratamento da Hepatite C são: Simeprevir (2ª geração de inibidor de protease), Daclatasvir (inibidor de NS5A) e o Sofosbuvir (inibidor de NS5B análogo nucleotídeo). A combinação dessas diferentes classes de DAAs permite maior eficácia no tratamento do $\mathrm{HCV}$, reduz o risco da emergência de resistência e também a duração do tratamento. O Sofosbuvir (SOF) é um potente inibidor de polimerase com elevada barreira genética, age como um terminador de cadeia dentro do sitio catalítico da NS5B, esse DAA é a base terapêutica para todos os genótipos do HCV. [42-44]

$\mathrm{Na}$ era dos DAAs, as diretrizes atuais sugerem regimes de tratamento semelhantes tanto para os pacientes co-infectados HCV/HIV como para os doentes monoinfectados com HCV. [45] Todavia, interações de entre DAAs e antirretrovirais (ARV) utilizados no tratamento da infecção pelo HIV precisam ser consideradas antes de iniciar qualquer tratamento. A principal interação entre drogas observada é a do Simeprevir (inibidor de protease NS3) com os ARV inibidores de protease e inibidores não análogos de nucleosídeo. [19] 


\subsubsection{Mecanismo de ação dos Inibidores de polimerase (NS5B) e variantes associadas à resistência}

As enzimas polimerase são essenciais no ciclo de vida dos vírus, pois participam do processo de replicação e da transcrição do genoma viral, e como consequência do papel chave que elas desempenham, são os principais alvos para as terapias antivirais. [46] $\mathrm{O}$ genoma do vírus da Hepatite $\mathrm{C}$ transcreve a sua própria polimerase, a qual é designada de RNA-polimerase RNAdependente (RpRd). [47]

A estrutura da polimerase se assemelha a uma mão direita em forma de concha composta por 3 domínios: a palma (Palm), os dedos (Fingers) e o polegar (Thumb). O domínio Palm é o mais conservado entre os diferentes tipos de polimerase, além disso, é onde está localizado o sítio ativo dessa enzima. Em contraste, o domínio Thumb é o mais variável (Figura 6). [48, 49]

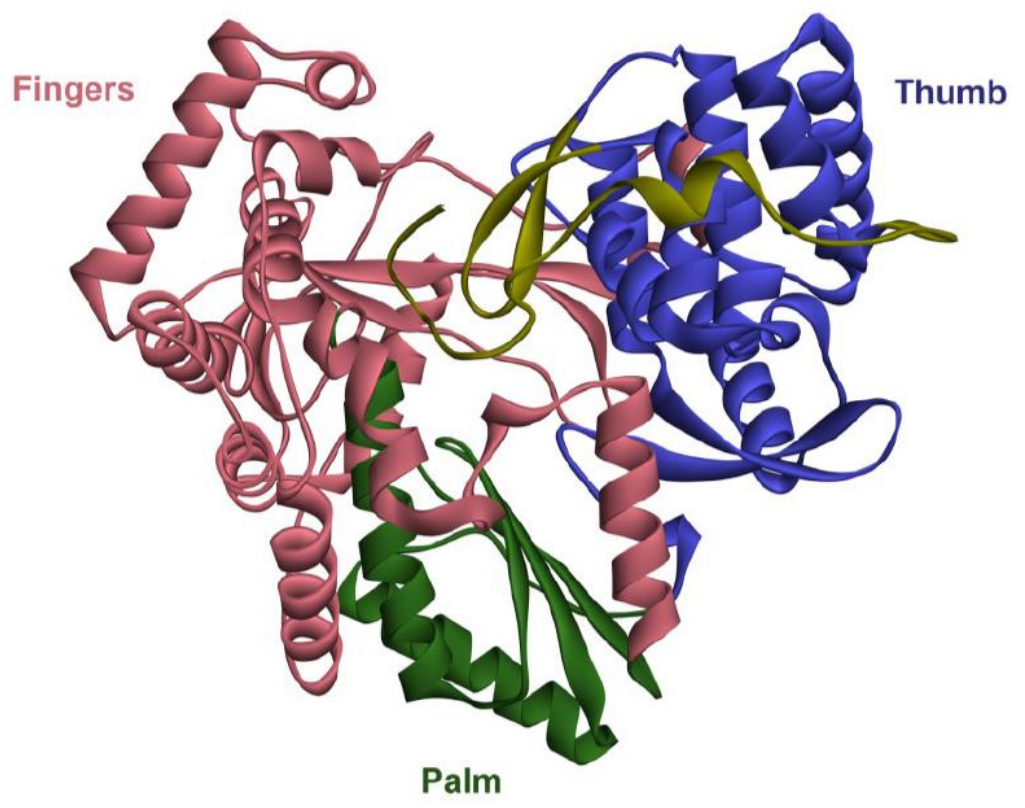

Figura 6 - Estrutura cristalográfica da RNA-polimerase RNA-dependente (NS5B do HCV). Domínios fingers (vermelho) e thumb (azul) envolvendo o sítio ativo dentro do domínio palm (verde). [49] 
Atualmente existem duas principais classes de inibidores da polimerase NS5B do HCV: os inibidores nucleosídeos (NIs, do inglês nucleoside inhibitors) e os não-nucleosídeos (NNIs, do inglês non-nucleoside inhibitors).

Os NIs mimetizam substratos naturais da polimerase NS5B ligam-se ao sítio ativo da enzima e atuam como terminadores de cadeia. As vantagens desses inibidores é que eles são capazes de inibir diferentes genótipos do $\mathrm{HCV}$, tem atividade antiviral mais forte e uma maior barreira genética para o surgimento de variantes resistentes aos medicamentos. [49-51] No entanto, esses inibidores podem também afetar o sítio ativo das polimerases do hospedeiro uma vez que compartilham características com diversos tipos de polimerases. O Sofosbuvir pertence a esta classe de drogas.[51]

Em ensaios pré-clínicos do Sofosbuvir foi observado que a substituição de uma Serina por uma Treonina na posição 282 (S282T) conferia resistência ao Sofosbuvir. In vitro, a RpRd portando a S282T apresentou uma afinidade reduzida ao análogo nucleosídeo. [52] Em uma análise recente envolvendo vários ensaios do Sofosbuvir, substituições na posição C316N/Y também foram associadas à resistência, especialmente em pacientes infectados pelo HCV-1b. [53] O mesmo estudo também identificou as variantes L159F e V321A como associadas à falta de resposta ao tratamento com o Sofosbuvir.[54-59]

Os NNIs são inibidores que se ligam a sítios alostéricos da polimerase, ou seja, fora do sítio ativo da enzima. Pelo menos quatro diferentes sítios de alostéricos de inibição da polimerase foram identificados, dois no Thumb (NNI1 e NNI-2) e dois na Palm (NNI-3 e NNI-4). Os NNI-3 e NNI-4 parecem inibir o início do processo de replicação enquanto os NNI-1 e NNI-2 inibem a etapa inicial da replicação antes da etapa de elongação ser iniciada. O medicamento 
Dasabuvir é o primeiro inibidor de Palm a ser aprovado para o tratamento de pacientes infectados pelo HCV genótipo 1. Substituições de aminoácido nas posições C316, M414, G554, S556 e D559 já foram associadas à resistência ao Dasabuvir. [60-62]

Ao mesmo tempo em que o desenvolvimento destas novas drogas antivirais promete melhorar a chance de sucesso do tratamento dos pacientes crônicos infectados pelo HCV, a emergência de variantes associadas à resistência representa um grande desafio ao sucesso da terapia antiviral atualmente proposta. [63] Informações sobre a presença dessas mutações em pacientes coinfectados pelo HIV-HCV são escassas. [61, 64-66]

Conhecer a população viral que circula em nosso meio antes da introdução dos novos fármacos é de extrema importância para que seja possível avaliar a real prevalência das mutações primárias e melhor compreender a evolução da dinâmica da infecção do HCV após a introdução destes inibidores. No sentido de melhor esclarecer essas questões é que foi realizado o presente estudo. 
Objetivo 


\section{OBJETIVO}

Mapeamento de mutações de resistência primária aos inibidores da polimerase (NS5B) do vírus da Hepatite $\mathrm{C}$ em pacientes monoinfectados pelo HCV e em pacientes coinfectados HCV/HIV. 
Métodos 


\section{MÉTODOS}

\subsection{Casuística}

O presente estudo foi submetido à Comissão de Ética para Análise de Projetos de Pesquisa (CAPPesq) da Diretoria Clínica do Hospital das Clínicas da Faculdade de Medicina da Universidade de São Paulo e foi aprovado por esta comissão (protocolo: 0704/11) (Apêndice I), posteriormente foi desmembrado para a execução do presente Mestrado sob aprovação da comissão supracitada (Apêndice II). O procedimento de coleta, manipulação de materiais biológicos e reagentes, além da utilização de equipamentos, estiveram em conformidade com as normas de biossegurança.

Foram selecionados 290 pacientes infectados pelo vírus da hepatite C genótipo 1, e estes pacientes foram distribuídos em dois grupos distintos:

Grupo 1 ( $n=147)$ : pacientes monoinfectados pelo HCV, regularmente acompanhados no ambulatório da Divisão de Moléstias Infecciosas e Parasitárias do Hospital das Clínicas da Faculdade de Medicina da USP - MI HCFMUSP.

Grupo 2 ( $n=143)$ : pacientes coinfectados pelo HCV e pelo vírus da imunodeficiência humana genótipo 1 (HIV-1). Estes pacientes foram provenientes de cinco centros de referência de doenças infecciosas no Brasil, são eles: Unidade de Referência de Tratamento de Doenças Infecciosas e Preveníveis da Faculdade de Medicina do ABC - URDIP, a Clínica de Especialidades de São Bernardo do Campo, o Serviço de Extensão ao Atendimento de Pacientes (HIV/AIDS) do Hospital das Clínicas da Faculdade de Medicina da Universidade de São Paulo - SEAP, o Centro de Referência e 
Treinamento DST/AIDS - CRTAIDS-SP e, por fim, o Ambulatório de Infectologia do Município de Caxias do Sul - RS.

Todos os pacientes selecionados para o presente estudo foram atendidos entre 2011 e 2013, eram virgens de tratamento para os agentes antivirais de ação direta (DAAs) e assinaram o Termo de Consentimento Livre e Esclarecimento (Apêndice III).

\section{Critérios de Inclusão}

- Diagnóstico de infecção crônica pelo HCV

- Diagnóstico de infecção pelo HIV-1 (Grupo 2)

- HCV-RNA detectável no soro.

\section{Critérios de exclusão}

- Diagnóstico de infecção crônica pelo vírus da hepatite B;

- Presença de quaisquer outras doenças hepáticas;

- Tratamento prévio com inibidores de protease ou qualquer outra droga Anti-HCV em investigação.

\subsection{Amostras}

Amostras de sangue periférico foram coletadas em tubos com gel (sem aditivos) e posteriormente armazenadas no Laboratório de Gastroenterologia e Hepatologia Tropical-IMT/USP. 


\subsection{Quantificação do HCV-RNA}

Uma alíquota de amostra foi enviada ao Laboratório de Biologia Molecular (LATE) do Hospital Israelita Albert Einstein para a quantificação do HCV-RNA. O teste COBAS AmpliPreP/COBASTaqman HCV da Roche versão 2.0 foi utilizado, a faixa de linearidade de quantificação foi 43 a $19.100 .000 \mathrm{UI} / \mathrm{mL}$ e o limite inferior de detecção para esse teste com faixa de positividade de $63 \%$ é de $2,5 \mathrm{UI} / \mathrm{mL}$.

\subsection{Amplificação da região NS5B do HCV}

O HCV-RNA foi extraído a partir de $140 \mu \mathrm{L}$ de soro utilizando-se o QIAamp ${ }^{\circledR}$ Viral RNA Kit (QIAGEN, Brasil - SP), foram seguidas as instruções do fabricante. Após a extração, o RNA foi submetido à reação de transcrição reversa (síntese do cDNA - DNA complementar) e 1ํPCR em uma única reação (PCR-OneStep) com volume total de $25 \mu \mathrm{L}$ utilizando-se: $12,5 \mu \mathrm{L}$ de $2 \mathrm{X}$ Reaction Mix e 0,5 $\mu \mathrm{L}$ da enzima SuperScript III High Fidelity One-Step ambos pertencentes ao RT-PCR kit (Invitrogen ${ }^{\mathrm{TM}}$, Thermo Fisher Brand, Carlsbad, USA), $5 \mu \mathrm{L}$ de cada um dos primers (Tabela 2), $5 \mu \mathrm{L}$ de água e por fim, $5 \mu \mathrm{L}$ de RNA. As condições da reação foram: $50{ }^{\circ} \mathrm{C}$ por 30 minutos (min); $94{ }^{\circ} \mathrm{C}$ por $2 \mathrm{~min}$, seguidos de 40 ciclos a $94^{\circ} \mathrm{C}$ por 15 segundos (s), $55^{\circ} \mathrm{C}$ por 30 s e $68^{\circ} \mathrm{C}$ por $3 \min$ e 20 s, e uma extensão final a $68^{\circ} \mathrm{C}$ por 5 min.

O produto obtido na primeira reação de amplificação foi submetido a uma segunda etapa de amplificação (nested-PCR), nessa etapa foram gerados dois fragmentos, um de 1200 pares de bases (pb) e outro de 570pb, parcialmente sobrepostos. Os primers utilizados nessas reações estão 
descritos na Tabela 2. As reações de nested-PCR foram realizadas em volume final de $50 \mu \mathrm{L}$ nas seguintes condições: $5 \mu \mathrm{L}$ de 10X High fidelity Buffer, $1,5 \mu \mathrm{L}$ de $\mathrm{MgSO}_{4}$ e $0.5 \mu \mathrm{L}$ de Taq Platinum High Fidelity ( $5 \mathrm{U} / \mu \mathrm{L}$ ) (Invitrogen ${ }^{\mathrm{TM}}$, Thermo Fisher Brand, Carlsbad, USA), $35 \mu \mathrm{L}$ de água DEPC, 0,2 mM de cada dNTP (Invitrogen ${ }^{\mathrm{TM}}$, Thermo Fisher Brand, Carlsbad, USA), $1 \mu \mathrm{L}$ de cada primer $(20 \mu \mathrm{M})$ e $5 \mu \mathrm{L}$ do produto da $1{ }^{\mathrm{a}} \mathrm{PCR}$.

Tabela 2 - Sequência de primers utilizados para a amplificação da região NS5B do HCV

\begin{tabular}{|c|c|c|c|}
\hline Reação & Primers $^{\#}$ & Sequência & $\begin{array}{c}\text { Posição de } \\
\text { nucleotídeos }\end{array}$ \\
\hline \multirow{2}{*}{$\mathrm{cDNA}+1^{\underline{a}} \mathrm{PCR}$} & & & $6076-6094$ \\
\hline & 9192_R & 5'-GGAGTCAGTTTGAGCTTGGT-3' & $9195-9214$ \\
\hline \multirow{4}{*}{$\begin{array}{l}\text { Nested PCR e } \\
\text { sequenciamento }\end{array}$} & 7498_F & 5'-TCCTCCATGCCCCCCCTNG-3' & $7498-8718$ \\
\hline & 8718_R & 5'-CGACGGACACRTTKGAGGAGCA-3' & $8718-7498$ \\
\hline & 8619_F & 5'-TTCACGGAGGCTATGACYAG-3' & $8619-9192$ \\
\hline & 9192_R & 5'-GGAGTGAGTTTGAGCTTGGT-3' & $9192-8619$ \\
\hline$\#_{0}$ & ri (2009) [ & & \\
\hline
\end{tabular}

\subsection{Identificação e quantificação dos produtos de PCR}

A identificação dos produtos amplificados na PCR foi realizada por eletroforese em gel de agarose com adição do corante SYBR Safe (Invitrogen ${ }^{\mathrm{TM}}$ Life Technologies, Carlsbad, CA, USA). Para tal foram misturados $4 \mu \mathrm{L}$ do produto final da PCR com $1 \mu \mathrm{L}$ do tampão 10X Bluejuice $^{\mathrm{TM}}$ Gel Loading 
Buffer (Invitrogem ${ }^{\mathrm{TM}}$, Thermo Fisher Brand, Carlsbad, CA, USA), a mistura foi aplicada em gel de agarose $2 \%$ preparado com tampão TAE $1 \mathrm{X}$ e $4,5 \mu \mathrm{L}$ do corante SYBR Safe para cada $100 \mathrm{~mL}$ de gel. A identificação e quantificação da banda específica foi realizada a partir da comparação com o padrão de tamanho (100 pb) e com o padrão de massa (Low DNA Mass Ladder Invitrogen TM, Thermo Fisher Brand, Carlsbad, CA, USA), respectivamente, conforme orientação do fabricante.

\subsection{Purificação dos produtos de PCR}

Os produtos de PCR da região NS5B passaram por uma etapa de purificação a partir da recuperação da banda específica no gel. Este procedimento mostrou-se necessário, pois a reação de amplificação desta região gerou produtos inespecíficos que interferem na qualidade do sequenciamento. Para tal, a banda que correspondia ao tamanho exato do produto amplificado foi cortada do gel e em seguida prosseguiu-se com a purificação que consistiu em diversas lavagens de centrifugações para a remoção do gel de agarose. Nesta etapa foi utilizado o kit MinElute ${ }^{\circledR} \mathrm{Gel}$ Extraction kit (QIAGEN, Biotecnologia Brasil Ltda., São Paulo), conforme instruções do fabricante.

\subsection{Reação de sequenciamento}

A técnica de sequenciamento utilizada foi derivada da metodologia de Sanger e colaboradores, 1977, utilizando-se dideoxinucleotídeos (ddNTPs) contendo marcadores fluorescentes. Os produtos de PCR purificados foram submetidos a uma reação de sequenciamento com volume final de $20 \mu \mathrm{L}$ nas 
seguintes condições: $4 \mu \mathrm{L}$ do reagente Big Dye ${ }^{\circledR}$ Terminator v3.1 (Applied Biosystems, Thermo Fisher Brand Foster City, CA, EUA), $4 \mu \mathrm{L}$ do tampão 5X, 2 $\mu \mathrm{L}$ de primer (1,6 $\mu \mathrm{M}), 2 \mu \mathrm{L}$ de DNA (20ng/ $\mu \mathrm{L})$ e $\mathrm{H}_{2} \mathrm{O}$ q.s.p. $20 \mu \mathrm{L}$. As amostras foram submetidas a 25 ciclos de variação de temperatura: $96^{\circ} \mathrm{C}$ por 30 segundos, $50^{\circ} \mathrm{C}$ por 15 segundos e $60^{\circ} \mathrm{C}$ por 4 minutos. Para cada amostra foram geradas sequências a partir das fitas de DNA senso e anti-senso.

Após a reação de sequenciamento, as amostras foram purificadas para remover resíduos de ddNTPs não incorporados ao DNA. Foram adicionados 80 $\mu \mathrm{L}$ de isopropanol $65 \%$ (Merck S.A) ao produto da reação, com posterior incubação por 15 minutos à temperatura ambiente (TA) e centrifugação a $13.000 \mathrm{rpm}$ por $45 \mathrm{~min}$ (TA). Após esta etapa, o isopropanol foi removido com o cuidado de não aspirar o precipitado. Em seguida foram realizadas duas lavagens por centrifugação com $150 \mu \mathrm{L}$ de etanol 60\% (Merck S.A), durante 15 min também a 13.000 rpm (TA). Após as lavagens, todo o etanol foi retirado, e as amostras colocadas em termobloco por aproximadamente 2 min a $94^{\circ} \mathrm{C}$, para a evaporação completa do etanol.

As amostras foram então ressuspensas em $10 \mu \mathrm{L}$ de formamida deionizada (Applied Biosystems, Foster City, CA, USA), incubadas a 95드 por 4 min para denaturação das fitas de DNA, em seguida foram colocadas em banho de gelo (choque térmico) e então levadas ao sequenciador ABI 3500 (Applied Biosystems, Thermo Fisher Brand Foster City, CA, EUA). 


\subsection{Análise das sequências}

As sequências obtidas (senso e antisenso) foram analisadas inicialmente utilizando o programa Electropherogram quality analysis disponível no site

http://asparagin.cenargen.embrapa.br/phph/, esse programa permite avaliar a qualidade das sequências e também montar uma sequência consenso, foram consideradas apenas as sequências que apresentaram qualidade maior do que 20 (score de qualidade do site).

A partir da sequência consenso de cada paciente foi realizado 0 alinhamento com todas as sequências utilizando o programa Clustal $X$ [67] dentro do programa Bioedit (versão 7.2.5). O alinhamento deste estudo foi realizado com referencia à sequência de referência H77 (NC_004102 - no de acesso GenBank). As sequências de nucleotídeos alinhadas foram convertidas em sequência de aminoácido no programa MEGA (Molecular Evolutionary Genetics Analysis versão 6.06) [68].

A partir do alinhamento da sequência de aminoácidos de cada amostra foi realizado o rastreamento de substituições associadas à resistência aos inibidores de polimerase (NS5B). Na tabela 3 estão listadas as principais substituições descritas na literatura. A posição 556 não pode ser analisada por estar fora da região de anelamento dos primers utilizados neste estudo. 
Tabela 3 - Substituições na NS5B associadas à resistência ao tratamento com inibidores de polimerase.

\begin{tabular}{ccc}
\hline Classe de medicamentos & $\begin{array}{c}\text { Substituições associadas à } \\
\text { resistência }\end{array}$ & Referências \\
\hline Inbidor nucleotídeo & & \\
Sofosbuvir & L159F & {$[53,59,69-73]$} \\
& $\mathrm{S} 282 \mathrm{~T} / \mathrm{R}$ & {$[69,73-78]$} \\
& $\mathrm{C} 316 \mathrm{~N} / \mathrm{Y}$ & {$[66,71,77,79,80]$} \\
$\mathrm{L} 320 \mathrm{~F}$ & {$[53,69,73]$} \\
$\mathrm{V} 321 \mathrm{~A}$ & {$[53,59,72]$} \\
& & \\
Inibidores não-nucleosídeo & $\mathrm{C} 316 \mathrm{~N} / \mathrm{Y}$ & {$[81]$} \\
Dasabuvir & $\mathrm{M} 414 \mathrm{~T} / \mathrm{I}$ & {$[82,83]$} \\
& $\mathrm{Y} 448 \mathrm{C} / \mathrm{H}$ & {$[82]$} \\
& $\mathrm{S} 556 \mathrm{G} / \mathrm{N} / \mathrm{R}$ & {$[82]$} \\
& $\mathrm{A} 421 \mathrm{~V}$ & {$[79,84,85]$} \\
Beclabuvir & $\mathrm{P} 495 \mathrm{~A} / \mathrm{L} / \mathrm{S} / \mathrm{T}$ & {$[86]$} \\
& & \\
\hline
\end{tabular}

\subsection{Análise estatística}

Para a análise estatística foi utilizado o programa GraphPad Prism 5 (GraphPad Software Inc., La Jolla, CA, USA). As análises descritivas foram realizadas de acordo com a natureza das variáveis. $O$ valor de $P<0,05$ foi considerado para indicar uma diferença estatisticamente significante. 
Resultados 


\section{RESULTADOS}

\subsection{Caracterização das amostras}

Ao todo foram incluídos 290 pacientes, entretanto a análise e 0 rastreamento de substituições na proteína NS5B foram realizados em 244 amostras de pacientes infectados pelo HCV genótipo 1 para os quais foram obtidas sequências com qualidade adequada, conforme mostrado na Figura 7. Destes, 133 eram pacientes monoinfectados e 111 pacientes coinfectados HCV-HIV (Figura 7).
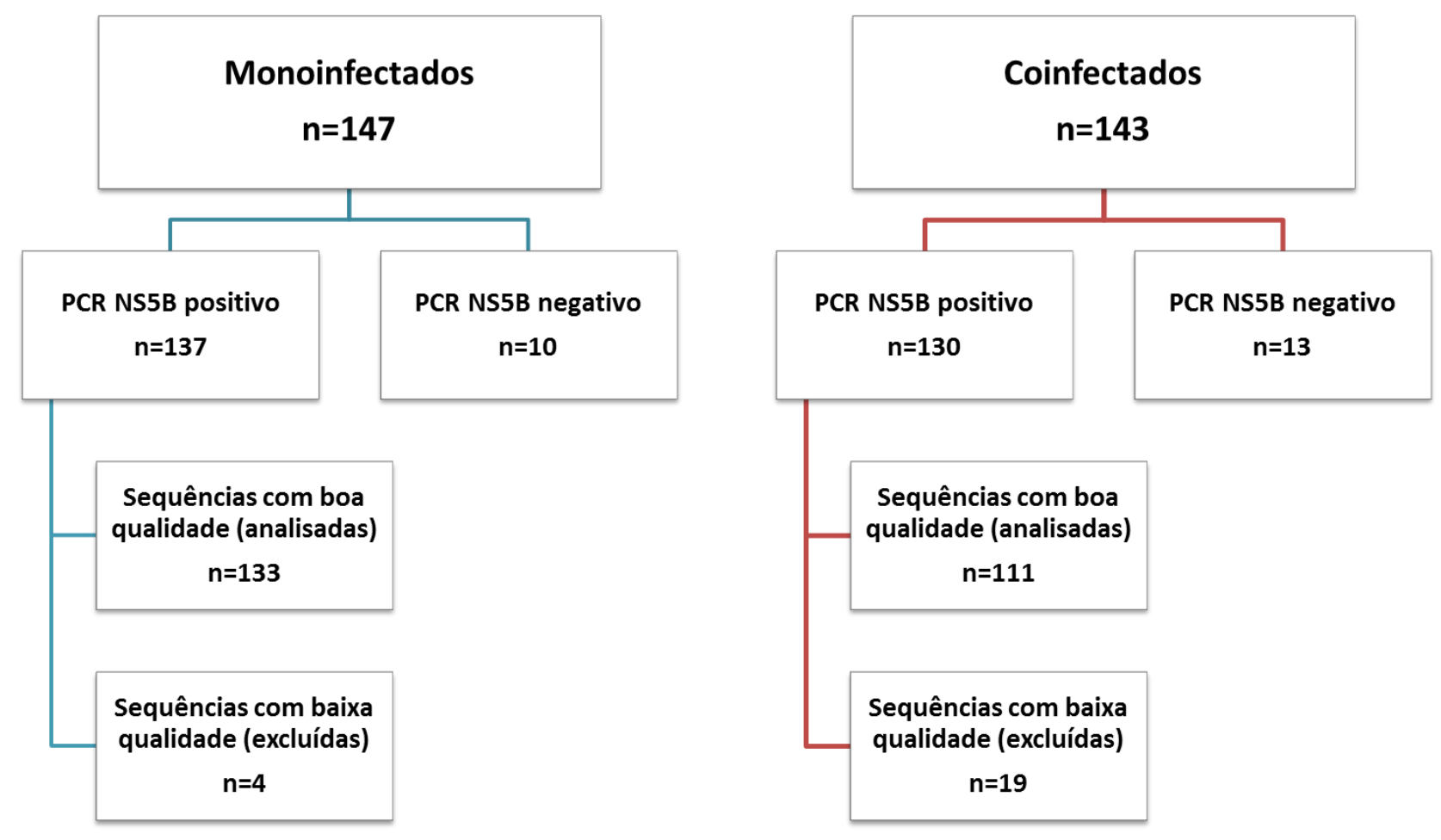

Figura 7: Fluxograma das etapas de processamento das amostras e seus respectivos resultados.

Considerando os subtipos do HCV, a maioria dos pacientes monoinfectados estava infectada pelo subtipo 1 b (70\%; $n=93)$ e $30 \%(n=40)$ infectados pelo subtipo 1a. Contrariamente, entre os pacientes coinfectados, a 
maioria estava infectada pelo subtipo 1a $83,8 \%(n=93)$ e $16,2 \% \quad(n=18)$ infectados pelo subtipo 1b. A comparação entre os valores do HCV-RNA (log $\mathrm{Ul} / \mathrm{ml})$ apresentou significância estatística $(P=0,025 ; 6,17$ vs 6,28 , mono e coinfectados, respectivamente).

No grupo de pacientes coinfectados também foram avaliados quais antiretrovirais foram utilizados para o tratamento da infecção pelo HIV (Tabela 4).

Tabela 4 - Antiretrovirais em uso por pacientes coinfectados (HCV-HIV)

\begin{tabular}{lcc}
\hline Antiretroviral & $\mathbf{n}$ & $\mathbf{( \% )}$ \\
\hline ITR análogos núcleos(t)ídicos & & \\
& & \\
Abacavir & 47 & 0,76 \\
Zidovudina & 122 & 35,61 \\
Lamivudina & 1 & 0,42 \\
Didanosina & 3 & 2,27 \\
Estavudina & 75 & 56,82 \\
Tenofovir & & \\
& & \\
ITR não análogos & & \\
núcleosídicos & 63 & 47,73 \\
Efavirenz & 1 & 0,76 \\
Nevirapina & & \\
& & \\
Inibidores da protease & 38 & 28,79 \\
Lopinavir / Ritonavir & 4 & 3,03 \\
Atazanavir & 16 & 12,12 \\
Atazanavir / Ritonavir & 2 & 1,52 \\
Fosamprenavir / Ritonavir & 3 & 2,27 \\
Darunavir / Ritonavir & & \\
& & \\
Inibidor da integrase & & 3,03 \\
Raltegravir & & \\
& & 5,3 \\
Sem TARV & 7 &
\end{tabular}

ITR - inibidores da transcriptase reversa ; TARV - terapia antiretroviral 
Observou-se que dentre as quatro classes de antiretrovirais utilizadas durante o tratamento desses pacientes, os análogos núcleos(t)dicos estiveram presentes na maioria das amostras avaliadas, sendo que a Lamivudina $(92,42 \%$ das amostras) e o Tenofovir $(56,82 \%)$ foram os medicamentos encontrados em um maior número de amostras, seguidos pelo Efavirenz (47,73\%), um análogo não-núcleos(t)dico. Os Inibidores de protease estiveram presentes em $47,73 \%$ das amostras, sendo o Lopinavir/Ritonavir os antiretrovirais mais representativos desta classe (28,79\%). A classe de antiretrovirais com menor representação dentre as amostras avaliadas foi a de Inibidores de integrase. Observou-se a presença do Raltegravir em apenas $3,03 \%$ das amostras. Sete pacientes foram diagnosticados como sem tratamento prévio para HIV com utilização de antiretrovirais (Tabela 4).

\subsection{Análise da frequência das mutações presentes na região NS5B do HCV}

O rastreamento de substituições de aminoácidos foi realizado entre as posições 159 e 495 da proteína NS5B do HCV (Tabela 5). A ocorrência natural de variantes nos resíduos S282, L320 e P495 não foi observada nas sequências analisadas neste estudo. As mutações encontradas no grupo de monoinfectados foram: L159F (16,1\% - 1b), C316N (16,3\% - 1b), V321I (1,2\% 1b) e A421V (21,4\% - 1a; 3,2\% - 1b), e no grupo de coinfectados foram: C316N (7,1\% - 1b), V321A (1,6\% - 1a), M414V (1,3\% - 1a); A421V (23,7\% - 1a; 6,3\% 1b), A421G (1,3\% - 1A); Y448H (1,3\% - 1a). 
Entre os pacientes monoinfectados, a região NS5B do HCV-1a apresentou menor número de RAVs quando comparada ao subtipo 1b, enquanto nos pacientes coinfectados foi observado o contrário.

Tabela 5 - Mutações encontradas na região NS5B do HCV

\begin{tabular}{|c|c|c|c|c|}
\hline \multirow{2}{*}{$\begin{array}{c}\text { Posições de } \\
\text { aminoácidos da } \\
\text { NS5B }\end{array}$} & \multicolumn{2}{|c|}{ HCV monoinfectados } & \multicolumn{2}{|c|}{ HIV-HCV coinfectados } \\
\hline & $1 a(n=41)$ & $1 b(n=92)$ & $1 a(n=93)$ & $1 b(n=18)$ \\
\hline L159F & - & $F(9 / 56 ; 16,1 \%)^{*}$ & - & - \\
\hline C316 & - & N (14/86; 16,3\%) & - & $\mathrm{N}(1 / 14 ; 7,1 \%)$ \\
\hline V321 & - & I (1/85; 1,2\%) & $A(1 / 62 ; 1,6 \%)$ & - \\
\hline M414 & - & - & $V(1 / 76 ; 1,3 \%)$ & - \\
\hline A421 & $\mathrm{V}(6 / 28 ; 21,4 \%)$ & V (2/63; 3,2\%) & $\begin{array}{c}\mathrm{V}(18 / 76 ; 23,7 \%) \\
\mathrm{G}(1 / 76 ; 1,3 \%)\end{array}$ & $\begin{array}{c}\mathrm{V}(1 / 16 ; 6,3 \%) \\
-\end{array}$ \\
\hline Y448 & - & - & $\mathrm{H}(1 / 76 ; 1,3 \%)$ & - \\
\hline
\end{tabular}

*número de variantes/total de sequências analisadas

Além das mutações descritas na Tabela 5, foi observada a ocorrência concomitante das variantes L159F e C316N em 8 pacientes monoinfectados pelo subtipo $1 \mathrm{~b}$ do $\mathrm{HCV}(8 / 56 ; 14,3 \%)$. Entre os coinfectados foi observada a ocorrência concomitante das variantes C316N e A421V em apenas 1 paciente coinfectado pelo HCV subtipo 1b (1/14; 7,1\%). A variante $\mathrm{C} 316 \mathrm{~N}$ foi a única que ocorreu em combinação com outras variantes na região analisada na proteína NS5B do HCV. 
Discussão 


\section{DISCUSSÃO}

Nos últimos anos, avanços significativos foram alcançados em relação ao tratamento da hepatite C crônica. Devido a grandes esforços em busca da melhoria da eficácia do tratamento da hepatite $\mathrm{C}$ tem sido observado um grande aprimoramento na segurança e tolerabilidade dos medicamentos. $O$ maior avanço na resposta terapêutica envolve o uso de inibidores de polimerase (Sofosbuvir e Dasabuvir), estudos clínicos utilizando os antivirais de ação direta têm demonstrado a importância dessa nova classe de medicamentos no manejo dos pacientes infectados pelo HCV. [87, 88]

O presente estudo apresenta achados relevantes frente ao atual cenário mundial do tratamento da hepatite $\mathrm{C}$ no qual o inibidor de polimerase tornou-se a base das novas terapias antivirais. Dentre os principais resultados obtidos no rastreamento de mutações de resistência na região NS5B do HCV estão: a ausência da ocorrência natural das mutações S282T, L302F e P495A/L/S em ambos os grupos de pacientes analisados (mono e coinfectados); a ocorrência concomitante das mutações L159F e C316N em pacientes monoinfectados pelo subtipo 1b do HCV; e a ocorrência da variante A421V nos dois grupos de pacientes analisados.

Em estudos pré-clínicos do Sofosbuvir foi observado que a substituição do aminoácido Serina (S) pelo aminoácido Treonina (T) na posição 282 da proteína NS5B conferiu resistência a este medicamento. Análises in vitro revelaram que esta substituição de aminoácidos reduz a afinidade desta proteína aos análogos nucleosídeos e também resulta em uma significativa redução da replicação viral. [89] Em estudo envolvendo pacientes 
monoinfectados tratados com sofosbuvir (ELECTRON), a substituição S282T foi detectada em apenas um paciente infectado com o subtipo 2 do HCV que teve recaída na quarta semana pós-tratamento. [90] A mutação S282T é gerada através de uma transversão, o que a torna muito menos frequente do que as mutações geradas por transição [75] e também tem sido demonstrada como de baixa prevalência em diversos estudos. No presente estudo, realizado antes desta droga estar disponível em nosso país, não foi observada a ocorrência da mutação S282T nos pacientes avaliados (mono e coinfectados).

Tendo em vista que a ação do Sofosbuvir é alterada pela variante S282T, e que a posição L159 interage potencialmente com a posição S282, presume-se que substituições na posição 159 alteram as interações entre as cadeias de aminoácidos levando a redução da inibição pelo Sofosbuvir. Análises realizadas durante a fase 3 dos estudos clínicos do Sofosbuvir identificaram o surgimento das variantes L159F e V321A $[59,72]$ associadas à resistência em pacientes infectados pelo HCV genótipo 3 após o início do tratamento. [70] Antes do início do tratamento, a variante L159F foi detectada em alguns pacientes infectados pelo HCV genótipo $1 \mathrm{~b}$ e os mesmos apresentaram falha terapêutica.

Em outro estudo de mutações de resistência de ocorrência natural, Paolucci e colaboradores (2013) [71], relatou que dos 30 pacientes com genótipo 1b analisados, 7 carregavam a variante L159F, sendo que desses 7, 1 indivíduo carregava também a mutação C316N. A combinação das variantes L159F e L320F ou C316N foi descrita por possuir grande efeito na eficácia do Sofosbuvir.[53, 73] Sabe-se que a posição C316 é altamente conservada no subtipo 1a do HCV e as substituições C316N e C316H têm menos chances de 
ocorrerem neste genótipo, pois cada uma delas precisa de duas mutações no códon para que essas substituições ocorram. [53] Além disso, ocorrência de mutações nessa posição pode afetar a ação de inibidores não nucleosídeos (NS5B-NNIs) da polimerase que tem como alvo a região Palm da NS5B. [91]

No presente estudo, a variante L320F não foi encontrada, no entanto a variante L159F foi identificada entre os indivíduos monoinfectados pelo HCV genótipo 1b, o mais interessante foi observar que 8 dos 9 pacientes com essa variante também apresentaram a variante $\mathrm{C} 316 \mathrm{~N}$, ou seja, a combinação L159F + C316N foi observada em nossa casuística, o que representa ocorrência natural de resistência aos inibidores de polimerase (Sofosbuvir e Dasabuvir) sendo um importante achado para pacientes virgens de tratamento. Adicionalmente, a mutação V321A foi encontrada em 1 paciente coinfectado pelo subtipo 1a do $\mathrm{HCV}$ e não respondedor ao tratamento prévio para HIV, outras variantes V321I e V321N também foram identificadas, mas em pacientes monoinfectados pelo HCV genótipo 1b. A posição 321 da proteína NS5B está localizada próxima ao sítio catalítico da polimerase viral e mudanças de aminoácido nesta região podem impedir o acesso dos inibidores de polimerase ao sítio de catálise interferindo assim no seu mecanismo de ação.[48, 49]

Substituições nos resíduos de aminoácidos localizados nas posições M414, A421, Y448, P495 e S556 também foram associadas com altos níveis resistência aos NS5B-NNIs. [92-94] No presente estudo não foram observadas substituições nos resíduos 414 e 495 da NS5B. A variante A421V é comumente observada entre os indivíduos infectados pelo HCV genótipo 1a e foi associada com resistência ao medicamento Beclabuvir. Nossos resultados revelaram que a mutação $A 421 \mathrm{~V}$ foi observada em maior frequência nos 
indivíduos infectados pelo HCV subtipo 1a (mono e coinfectados), no entanto também foi observada em pacientes infectados pelo HCV genótipo 1b. A importância desse achado é questionável, pois o medicamento Beclabuvir foi recentemente descontinuado durante a fase III do estudo clínico. [79, 94, 95]

Paolucci e colaboradores (2013) [71] observou a variante $\mathrm{Y} 448 \mathrm{H}$ em apenas um indivíduo coinfectado HIV-HCV em um estudo que avaliou a ocorrência natural de mutações na região NS5B. Todavia, neste estudo não foi observada uma maior ocorrência de mutações de resistência em coinfectados do que em monoinfectados. Nosso estudo apresentou um resultado similar, no qual apenas 1 paciente coinfectado pelo subtipo 1a apresentou a variante Y448H. Esta é uma mutação de resistência ao Dasabuvir, uma droga que faz parte de um esquema de tratamento já aprovado em muitos países do mundo.

Atualmente no mundo a aplicação de testes para o rastreamento de mutações de resistência antes do início do tratamento não é recomendada [96], ao menos que o paciente já tenha apresentado falha terapêutica aos DAAs. Nesse caso o rastreamento de mutações de resistência é indicado para auxiliar no re-tratamento, pois permitirá a escolha da melhor opção terapêutica e o acompanhamento do perfil viral. Estas diretrizes estão sendo cogitadas por muitos pesquisadores especialmente para os inibidores de NS5A e para algumas RAVs importantes para alguns inibidores de NS3, em especial, a Q80K, que tem um efeito importante para o Simeprevir. Para as RAVs que atuam sobre os inibidores de NS5B, não existe nenhuma diretriz que proponha sua detecção rotineira antes do início do tratamento [63].

O impacto real da presença das variantes virais na resposta ao tratamento aqui no Brasil ainda será avaliado, uma vez que a aprovação e 
utilização dos novos DAAs ocorreu no final de 2015. Na era dos DAAs, as diretrizes atuais sugerem regimes de tratamento semelhantes tanto para os pacientes co-infectados HCV/HIV como para os doentes monoinfectados com HCV. [45]

Apesar do rastreamento de variantes não ser recomendado antes do início do tratamento, os resultados aqui apresentados demonstram que a ocorrência natural de variantes existe e o uso dos novos medicamentos na prática clínica permitirá compreender a dinâmica da infecção e o real impacto dessas variantes na resposta ao tratamento. Esse conhecimento de "vida real" é fundamental para o estabelecimento de estratégias terapêuticas que minimizem a seleção de variantes resistentes. 
Conclusão 


\section{CONCLUSÃO}

$\checkmark$ A mutação S282T não foi encontrada entre os pacientes avaliados no presente estudo;

$\checkmark$ Outras variantes associadas à resistência (L159F, C316N e A421V) foram observadas tanto no grupo de coinfectados como no grupo de monoinfectados;

$\checkmark$ A região NS5B do HCV-1a dos pacientes coinfectados apresentou maior número de RAVs quando comparada à dos monoinfectados;

$\checkmark$ O o real impacto dessas variantes na resposta ao tratamento aos DAAs ainda precisa determinado. 
Referências Bibliográficas 


\section{REFERÊNCIAS BIBLIOGRÁFICAS}

1. Bukh, J., R.H. Miller, and R.H. Purcell, Biology and genetic heterogeneity of hepatitis C virus. Clin Exp Rheumatol, 1995. 13 Suppl 13: p. S3-7.

2. Pawlotsky, J.M., Genetic heterogeneity and properties of hepatitis $C$ virus, in Acta Gastroenterol Belg. 1998. p. 189-91.

3. Tellinghuisen, T.L., et al., Studying hepatitis $C$ virus: making the best of a bad virus. J Virol, 2007. 81(17): p. 8853-67.

4. Cristina, J. and R. Colina, Evidence of structural genomic region recombination in Hepatitis C virus. Virol J, 2006. 3: p. 53.

5. Mauss, S., D. Hueppe, and U. Alshuth, Reply. Hepatology.

6. Ray, R.B. and T. Kanda, Inhibition of HCV replication by small interfering RNA. Methods Mol Biol, 2009. 510: p. 251-62.

7. Katsoulidou, A., et al., Molecular epidemiology of hepatitis C virus (HCV) in Greece: temporal trends in HCV genotype-specific incidence and molecular characterization of genotype 4 isolates. J Viral Hepat, 2006. 13(1): p. 19-27.

8. Pasquier, C., et al., Distribution and heterogeneity of hepatitis $C$ genotypes in hepatitis patients in Cameroon. J Med Virol, 2005. 77(3): p. 390-8.

9. Lole, K.S., et al., Comparison of hepatitis C virus genotyping by 5' noncoding region- and core-based reverse transcriptase PCR assay with sequencing and use of the assay for determining subtype distribution in India. J Clin Microbiol, 2003. 41(11): p. 5240-4.

10. Simmonds, P., The origin of hepatitis C virus. Curr Top Microbiol Immunol. 369: p. 1-15.

11. Jackowiak, P., et al., Phylogeny and molecular evolution of the hepatitis $C$ virus. Infect Genet Evol. 21: p. 67-82.

12. Echevarria, J.M. and P. Leon, Epidemiology of viruses causing chronic hepatitis among populations from the Amazon Basin and related ecosystems. Cad Saude Publica, 2003. 19(6): p. 1583-91.

13. Alter, M.J., Epidemiology of hepatitis C virus infection. World J Gastroenterol, 2007. 13(17): p. 2436-41.

14. Seeff, L.B., Natural history of chronic hepatitis C. Hepatology, 2002. 36(5 Suppl 1): p. S35-46.

15. Hajarizadeh, B., J. Grebely, and G.J. Dore, Epidemiology and natural history of HCV infection. Nat Rev Gastroenterol Hepatol. 10(9): p. 553-62.

16. Focaccia, R., et al., Estimated Prevalence of Viral Hepatitis in the General Population of the Municipality of Sao Paulo, Measured by a Serologic Survey of a Stratified, Randomized and Residence-Based Population. Braz J Infect Dis, 1998. 2(6): p. 269-284. 
17. Pereira, L.M., et al., Prevalence and risk factors of Hepatitis $C$ virus infection in Brazil, 2005 through 2009: a cross-sectional study. BMC Infect Dis, 2010. 13: p. 60.

18. Soriano, V., et al., Care of HIV patients with chronic hepatitis B: updated recommendations from the HIV-Hepatitis B Virus International Panel. Aids, 2008. 22(12): p. 1399-410.

19. Mandorfer, M., et al., Advances in the management of HIV/HCV coinfection. Hepatol Int, 2016.

20. Braga, W.S., et al., Low prevalence of hepatitis $B$ virus, hepatitis $D$ virus and hepatitis $C$ virus among patients with human immunodeficiency virus or acquired immunodeficiency syndrome in the Brazilian Amazon basin. Rev Soc Bras Med Trop, 2006. 39(6): p. 519-22.

21. Sherman, K.E., et al., Hepatitis $C$ Virus prevalence among patients infected with Human Immunodeficiency Virus: a cross-sectional analysis of the US adult AIDS Clinical Trials Group. Clin Infect Dis, 2002. 34(6): p. 831-7.

22. Sulkowski, M.S. and D.L. Thomas, Hepatitis $C$ in the HIV-infected patient. Clin Liver Dis, 2003. 7(1): p. 179-94.

23. Sulkowski, M.S. and D.L. Thomas, Hepatitis C in the HIV-Infected Person. Ann Intern Med, 2003. 138(3): p. 197-207.

24. Boesecke, C. and J.K. Rockstroh, Acute hepatitis $C$ in patients with HIV. Semin Liver Dis, 2012. 32(2): p. 130-7.

25. Kamal, S.M., Acute hepatitis C: a systematic review. Am J Gastroenterol, 2008. 103(5): p. 1283-97; quiz 1298.

26. Mendes-Correa, M.C., et al., Prevalence of hepatitis $B$ and $C$ in the sera of patients with HIV infection in Sao Paulo, Brazil. Rev Inst Med Trop Sao Paulo, 2000. 42(2): p. 81-5.

27. Mendes-Correa, M.C., et al., Barriers to treatment of hepatitis $C$ in HIV/HCV coinfected adults in Brazil. Braz J Infect Dis, 2010. 14(3): p. 237-41.

28. Victoria, M.B., et al., Epidemiology of HIV/HCV coinfection in patients cared for at the Tropical Medicine Foundation of Amazonas. Braz J Infect Dis, 2010. 14(2): p. $135-40$.

29. Chu, C.M., C.T. Yeh, and Y.F. Liaw, Viral superinfection in previously unrecognized chronic carriers of hepatitis $B$ virus with superimposed acute fulminant versus nonfulminant hepatitis. J Clin Microbiol, 1999. 37(1): p. 235-7.

30. Farci, P., et al., Hepatitis C virus-associated fulminant hepatic failure. N Engl J Med, 1996. 335(9): p. 631-4.

31. Koretz, R.L., et al., Non- $A$, non-B posttransfusion hepatitis: comparing $C$ and non-C hepatitis. Hepatology, 1993. 17(3): p. 361-5. 
32. Chen, T.Y., et al., Meta-analysis: increased mortality associated with hepatitis $C$ in HIV-infected persons is unrelated to HIV disease progression. Clin Infect Dis, 2009. 49(10): p. 1605-15.

33. Weber, R., et al., Liver-related deaths in persons infected with the human immunodeficiency virus: the D:A:D study. Arch Intern Med, 2006. 166(15): p. 1632-41.

34. Hadziyannis, S.J., et al., Peginterferon-alpha2a and ribavirin combination therapy in chronic hepatitis C: a randomized study of treatment duration and ribavirin dose. Ann Intern Med, 2004. 140(5): p. 346-55.

35. Manns, M.P., M. Cornberg, and H. Wedemeyer, Current and future treatment of hepatitis C. Indian J Gastroenterol, 2001. 20 Suppl 1: p. C47-51.

36. Sarrazin, C. and S. Zeuzem, Resistance to direct antiviral agents in patients with hepatitis $C$ virus infection. Gastroenterology. 138(2): p. 447-62.

37. Poordad, F., et al., Boceprevir for untreated chronic HCV genotype 1 infection. $\mathrm{N}$ Engl J Med. 364(13): p. 1195-206.

38. Sherman, K.E., et al., Response-guided telaprevir combination treatment for hepatitis C virus infection. N Engl J Med. 365(11): p. 1014-24.

39. Lamarre, D., et al., An NS3 protease inhibitor with antiviral effects in humans infected with hepatitis C virus. Nature, 2003. 426(6963): p. 186-9.

40. Zeuzem, S., et al., Telaprevir for retreatment of HCV infection. N Engl J Med, 2012. 364(25): p. 2417-28.

41. Asselah, T., et al., Direct-acting antivirals for the treatment of hepatitis $C$ virus infection: optimizing current IFN-free treatment and future perspectives. Liver Int, 2016. 36 Suppl 1: p. 47-57.

42. Asselah, T., Daclatasvir plus sofosbuvir for HCV infection: an oral combination therapy with high antiviral efficacy. J Hepatol, 2014. 61(2): p. 435-8.

43. Asselah, T., Sofosbuvir for the treatment of hepatitis $C$ virus. Expert Opin Pharmacother, 2014. 15(1): p. 121-30.

44. Asselah, T. and P. Marcellin, Second-wave IFN-based triple therapy for HCV genotype 1 infection: simeprevir, faldaprevir and sofosbuvir. Liver Int, 2014. 34 Suppl 1: p. 60-8.

45. Rockstroh, J.K., Optimal therapy of HIV/HCV co-infected patients with direct acting antivirals. Liver Int, 2015. 35 Suppl 1: p. 51-5.

46. Choi, K.H., Viral polymerases. Adv Exp Med Biol, 2012. 726: p. 267-304.

47. Bartenschlager, R. and V. Lohmann, Replication of hepatitis C virus. J Gen Virol, 2000. 81(Pt 7): p. 1631-48.

48. Sesmero, E. and I.F. Thorpe, Using the Hepatitis C Virus RNA-Dependent RNA Polymerase as a Model to Understand Viral Polymerase Structure, Function and Dynamics. Viruses, 2015. 7(7): p. 3974-94. 
49. Eltahla, A.A., et al., Inhibitors of the Hepatitis C Virus Polymerase; Mode of Action and Resistance. Viruses, 2015. 7(10): p. 5206-24.

50. Membreno, F.E. and E.J. Lawitz, The HCV NS5B nucleoside and non-nucleoside inhibitors. Clin Liver Dis. 15(3): p. 611-26.

51. Caillet-Saguy, C., et al., Polymerases of hepatitis $C$ viruses and flaviviruses: structural and mechanistic insights and drug development. Antiviral Res, 2014. 105: p. 8-16.

52. Feld, J.J., Interferon-free strategies with a nucleoside/nucleotide analogue. Semin Liver Dis, 2014. 34(1): p. 37-46.

53. Donaldson, E.F., et al., Clinical evidence and bioinformatics characterization of potential hepatitis $C$ virus resistance pathways for sofosbuvir. Hepatology, 2015. 61(1): p. 56-65.

54. Ali, S., et al., Selected replicon variants with low-level in vitro resistance to the hepatitis C virus NS5B polymerase inhibitor PSI-6130 lack cross-resistance with R1479. Antimicrob Agents Chemother, 2008. 52(12): p. 4356-69.

55. Klumpp, K., et al., The novel nucleoside analog R1479 (4'-azidocytidine) is a potent inhibitor of NS5B-dependent RNA synthesis and hepatitis $C$ virus replication in cell culture. J Biol Chem, 2006. 281(7): p. 3793-9.

56. Le Pogam, S., et al., In vitro selected Con1 subgenomic replicons resistant to 2'C-methyl-cytidine or to R1479 show lack of cross resistance. Virology, 2006. 351(2): p. 349-59.

57. Pierra, C., et al., $\mathrm{Nm} 283$, an efficient prodrug of the potent anti-HCV agent 2'-Cmethylcytidine. Nucleosides Nucleotides Nucleic Acids, 2005. 24(5-7): p. 76770.

58. Pockros, P., et al., High relapse rate seen at week 72 for patients treated with R1626 combination therapy. Hepatology, 2008. 48(4): p. 1349-50.

59. Svarovskaia, E.S., et al., Infrequent development of resistance in genotype 1-6 hepatitis $C$ virus-infected subjects treated with sofosbuvir in phase 2 and 3 clinical trials. Clin Infect Dis, 2014. 59(12): p. 1666-74.

60. Tomei, L., et al., Mechanism of action and antiviral activity of benzimidazolebased allosteric inhibitors of the hepatitis $C$ virus RNA-dependent RNA polymerase. J Virol, 2003. 77(24): p. 13225-31.

61. Gaudieri, S., et al., Hepatitis $C$ virus drug resistance and immune-driven adaptations: relevance to new antiviral therapy. Hepatology, 2009. 49(4): p. 1069-82.

62. Poordad F. , E.L., K.V. Kowdley, G.T. Everson, B. Freilich, D. Cohen, S. Siggelkow, M. Heckaman, R. Menon, T. Pilot- Matias, T. Podsadecki, B. Bernstein, 12-week interferon-free regimen of abt-450/r +abt-333 +ribavirin achieved svr12 in more than $90 \%$ of treatment-naive hov genotype-1-infected subjects and $47 \%$ of 
previous non-responders. Journal of Hepatology, 2012. 56(Supplement 2): p. S549-S550.

63. Sarrazin, C., The importance of resistance to direct antiviral drugs in HCV infection in clinical practice. J Hepatol, 2016. 64(2): p. 486-504.

64. Halfon, P., et al., Mutation rate in hepatitis C virus NS3 protease is not influenced by HIV-1 protease inhibitor therapy. Aids, 2008. 22(13): p. 1694-6.

65. Morsica, G., et al., Detection of hepatitis $C$ mutants with natural resistance to NS3/4A protease inhibitors in HIV/HCV-coinfected individuals treated with antiretroviral therapy. J Acquir Immune Defic Syndr, 2009. 51(1): p. 106-8.

66. Castilho, M.C., et al., Association of hepatitis C virus NS5B variants with resistance to new antiviral drugs among untreated patients. Mem Inst Oswaldo Cruz, 2011. 106(8): p. 968-75.

67. Thompson, J.D., et al., The CLUSTAL_X windows interface: flexible strategies for multiple sequence alignment aided by quality analysis tools. Nucleic Acids Res, 1997. 25(24): p. 4876-82.

68. Kumar, S., et al., MEGA2: molecular evolutionary genetics analysis software. Bioinformatics, 2001. 17(12): p. 1244-5.

69. Gane, E.J., et al., Mericitabine and ritonavir-boosted danoprevir with or without ribavirin in treatment-naive HCV genotype 1 patients: INFORM-SVR study. Liver Int, 2015. 35(1): p. 79-89.

70. Nguyen, L.T., et al., Naturally occurring HCV NS5A/B inhibitor resistanceassociated mutations to direct-acting antivirals. Antivir Ther, 2016.

71. Paolucci, S., et al., Naturally occurring resistance mutations to inhibitors of HCV NS5A region and NS5B polymerase in DAA treatment-naive patients. Virol J, 2013. 10: p. 355.

72. Svarovskaia, E.S., et al., L159F and V321A Sofosbuvir-Associated Hepatitis C Virus NS5B Substitutions. J Infect Dis, 2015.

73. Tong, X., et al., In vivo emergence of a novel mutant L159F/L320F in the NS5B polymerase confers low-level resistance to the HCV polymerase inhibitors mericitabine and sofosbuvir. J Infect Dis, 2014. 209(5): p. 668-75.

74. Chang, W., et al., Discovery of PSI-353661, a Novel Purine Nucleotide Prodrug for the Treatment of HCV Infection. ACS Med Chem Lett, 2011. 2(2): p. 130-5.

75. Franco, S., et al., No detection of the NS5B S282T mutation in treatment-naive genotype $1 \mathrm{HCV} / \mathrm{HIV}-1$ coinfected patients using deep sequencing. J Clin Virol, 2013. 58(4): p. 726-9.

76. Le Pogam, S., et al., RG7128 alone or in combination with pegylated interferonalpha2a and ribavirin prevents hepatitis $C$ virus (HCV) Replication and selection of resistant variants in HCV-infected patients. J Infect Dis, 2010. 202(10): p. 1510-9. 
77. Ludmerer, S.W., et al., Replication fitness and NS5B drug sensitivity of diverse hepatitis $C$ virus isolates characterized by using a transient replication assay. Antimicrob Agents Chemother, 2005. 49(5): p. 2059-69.

78. Premoli, C. and A. Aghemo, Directly acting antivirals against hepatitis $C$ virus: mechanisms of action and impact of resistant associated variants. Minerva Gastroenterol Dietol, 2015. 62(1): p. 76-87.

79. Aissa Larousse, J., et al., Natural prevalence of hepatitis C virus (HCV) variants resistant to protease and polymerase inhibitors in patients infected with $\mathrm{HCV}$ genotype 1 in Tunisia. J Med Virol, 2014. 86(8): p. 1350-9.

80. Plaza, Z., et al., Impact of antiretroviral therapy on the variability of the HCV NS5B polymerase in HIV/HCV co-infected patients. J Antimicrob Chemother, 2011. 66(12): p. 2838-42.

81. Krishnan, P., et al., Resistance analysis of baseline and treatment-emergent variants in hepatitis $C$ virus genotype 1 in the AVIATOR study with paritaprevirritonavir, ombitasvir, and dasabuvir. Antimicrob Agents Chemother, 2015. 59(9): p. 5445-54.

82. Kati, W., et al., In vitro activity and resistance profile of dasabuvir, a nonnucleoside hepatitis $C$ virus polymerase inhibitor. Antimicrob Agents Chemother, 2015. 59(3): p. 1505-11.

83. Mo, H., et al., Mutations conferring resistance to a hepatitis C virus (HCV) RNAdependent RNA polymerase inhibitor alone or in combination with an HCV serine protease inhibitor in vitro. Antimicrob Agents Chemother, 2005. 49(10): p. 4305-14.

84. Chen, M., et al., Multiple Introduction and Naturally Occuring Drug Resistance of HCV among HIV-Infected Intravenous Drug Users in Yunnan: An Origin of China's HIV/HCV Epidemics. PLoS One, 2015. 10(11): p. e0142543.

85. Sede, M.M., N.L. Laufer, and J. Quarleri, Previous failure of interferon-based therapy does not alter the frequency of HCV NS3 protease or NS5B polymerase inhibitor resistance-associated variants: longitudinal analysis in $\mathrm{HCV} / \mathrm{HIV}$ coinfected patients. Int J Antimicrob Agents, 2015. 46(2): p. 219-24.

86. Rigat, K.L., et al., Mechanism of inhibition for BMS-791325, a novel nonnucleoside inhibitor of hepatitis C virus NS5B polymerase. J Biol Chem, 2014. 289(48): p. 33456-68.

87. McQuaid, T., C. Savini, and S. Seyedkazemi, Sofosbuvir, a Significant Paradigm Change in HCV Treatment. J Clin Transl Hepatol, 2015. 3(1): p. 27-35.

88. Gamal, N. and P. Andreone, Working together to tackle HCV infection: ombitasvir/paritaprevir/ritonavir and dasabuvir combination. Drugs Today (Barc), 2015. 51(5): p. 303-14. 
89. Lam, A.M., et al., Genotype and subtype profiling of PSI-7977 as a nucleotide inhibitor of hepatitis C virus. Antimicrob Agents Chemother, 2012. 56(6): p. 3359-68.

90. Gane, E.J., et al., Nucleotide polymerase inhibitor sofosbuvir plus ribavirin for hepatitis C. N Engl J Med, 2013. 368(1): p. 34-44.

91. Hang, J.Q., et al., Slow binding inhibition and mechanism of resistance of nonnucleoside polymerase inhibitors of hepatitis C virus. J Biol Chem, 2009. 284(23): p. 15517-29.

92. Legrand-Abravanel, F., et al., Naturally occurring substitutions conferring resistance to hepatitis $C$ virus polymerase inhibitors in treatment-naive patients infected with genotypes 1-5. Antivir Ther, 2009. 14(5): p. 723-30.

93. Halfon, P. and C. Sarrazin, Future treatment of chronic hepatitis $C$ with direct acting antivirals: is resistance important? Liver Int, 2012. 32 Suppl 1: p. 79-87.

94. Bartels, D.J., et al., Hepatitis $C$ virus variants with decreased sensitivity to directacting antivirals (DAAs) were rarely observed in DAA-naive patients prior to treatment. J Virol, 2013. 87(3): p. 1544-53.

95. Everson, G.T., et al., Daclatasvir + asunaprevir + beclabuvir +/- ribavirin for chronic HCV genotype 1-infected treatment-naive patients. Liver Int, 2016. 36(2): p. 189-97.

96. EASL, EASL Recommendations on Treatment of Hepatitis C 2015. J Hepatol, 2015. 63(1): p. 199-236. 
Apêndices 


\section{Apêndice I}

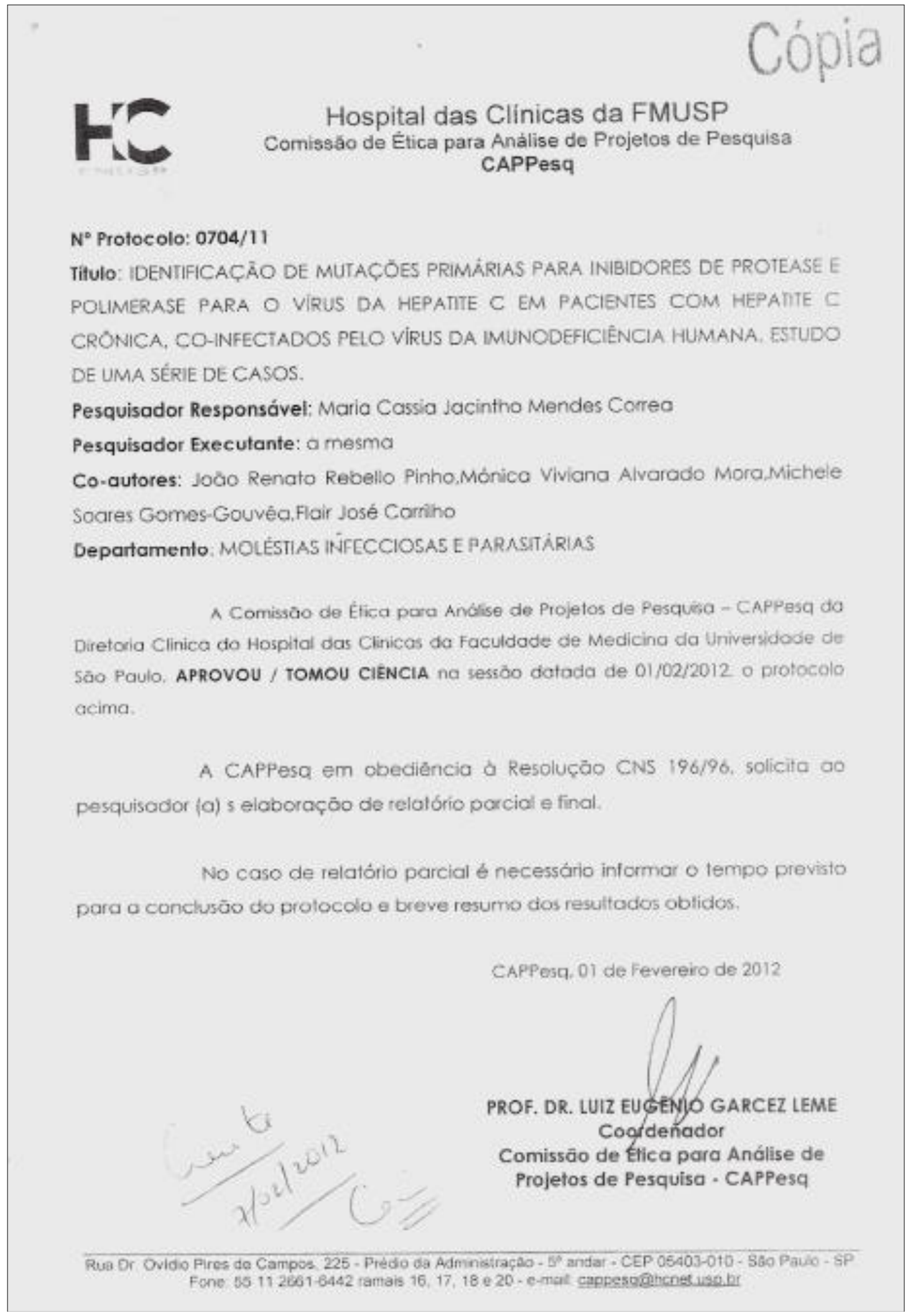




\section{Apêndice II}

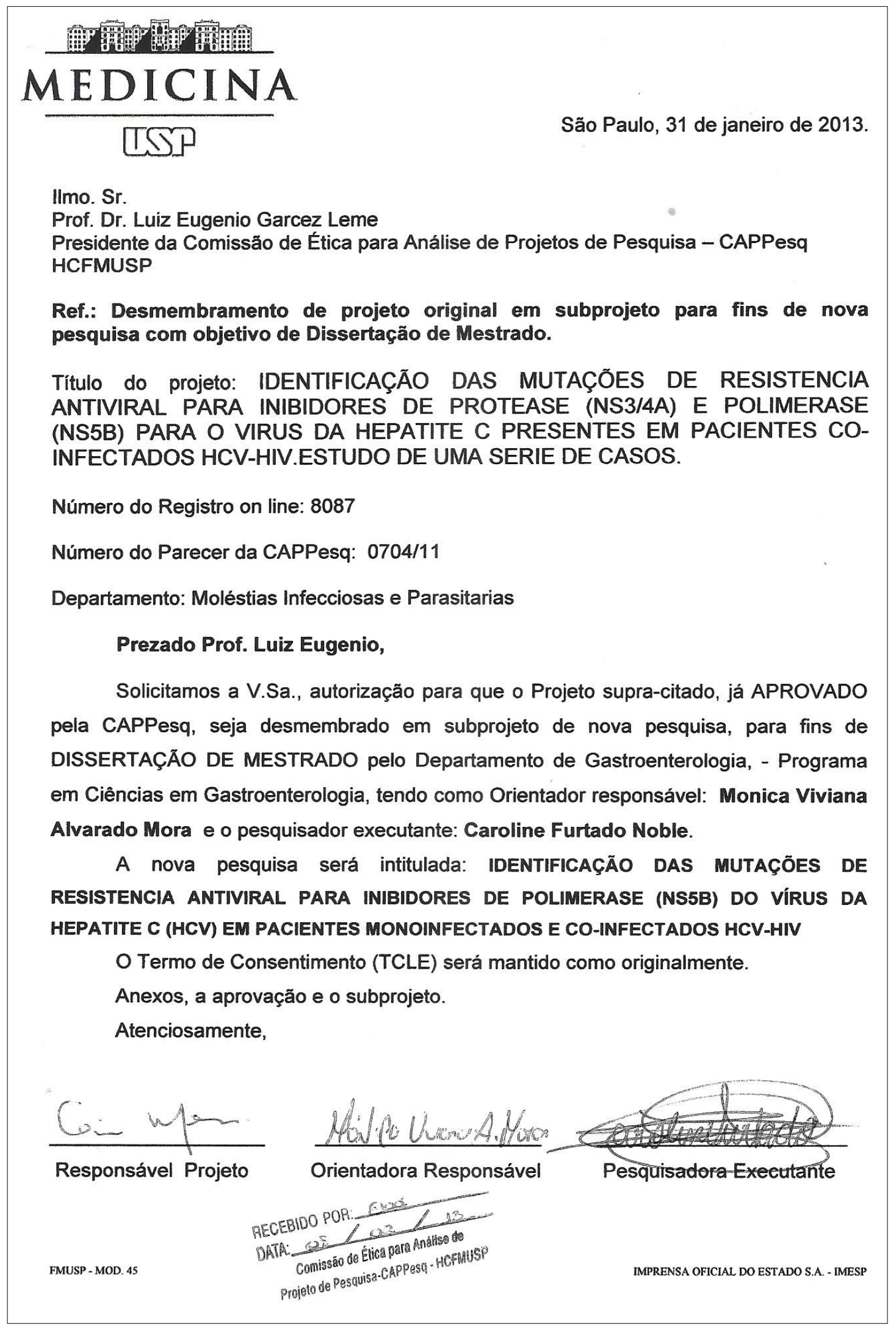




\section{Apêndice III}

\section{TERMO DE CONSENTIMENTO LIVRE E ESCLARECIDO}

\section{I - DADOS DE IDENTIFICAÇÃO DO PACIENTE OU RESPONSÁVEL LEGAL}

\section{NOME DO PACIENTE:}

DOC. DE IDENTIDADE No

SEXO: DATA NASC:

ENDEREÇO

No. APTO

BAIRRO

CIDADE:

CEP:

TELEFONE:

2. RESPONSÁVEL LEGAL:

NATUREZA: (grau de parentesco, tutor, curador etc.)

DOC. DE IDENTIDADE: $\quad$ SEXO: DATA NASC:

ENDEREÇO No. APTO

BAIRRO CIDADE:

CEP: $\quad$ TELEFONE:

\section{II - DADOS SOBRE A PESQUISA CLINICA}

1.TITULO DO PROTOCOLO DE PESQUISA

Identificação de mutações primárias para inibidores de protease e polimerase para o virus da hepatite $C$ em pacientes com hepatite $C$ crônica, co-infectados pelo vírus da imunodeficiência humana. Estudo de uma série de casos.

2. PESQUISADOR: Dra. Maria Cássia Jacintho Mendes Corrêa

CARGO/FUNÇÃo: Médico Assistente

INSC. CONS. REGIONAL No.52275.

UNIDADE DA FMABC- CEPES-URDIP

3. AVALIAÇÃO DO RISCO DA PESQUISA:

(probabilidade de que o indivíduo sofra algum dano como conseqüência imediata ou tardia do estudo)

SEM RISCOD: $\quad$ RISCO MÍNIMO: X RISCO MÉDIO: $\square$ RISCO MAIOR:

4. DURAÇÃO DA PESQUISA: Doze meses para coleta das amostras 


\section{III - REGISTRO DAS EXPLICAÇÕES DO PESQUISADOR AO PACIENTE OU EU REPRESENTANTE LEGAL}

\section{Justificativa e Objetivos da pesquisa}

Você está sendo convidado a participar desse estudo, pois nós sabemos que você é infectado pelo vírus da hepatite $\mathrm{C}$. $\mathrm{O}$ objetivo de nosso estudo é saber se entre as pessoas que têm a infecção pelo vírus da hepatite $\mathrm{C}$, existem pessoas com mutações ou "variações" desse vírus que possam ser naturalmente "resistentes" aos novos medicamentos que estão sendo propostos para o tratamento dessa infeção. Ou seja, queremos saber se entre nós existem pessoas que tenham hepatite $C_{r}$ e que já possam ter resistência aos novos medicamentos que vão começar a ser usados em quem precisa tratar a hepatite $\mathrm{C}$.

\section{Procedimentos}

Para poder participar deste estudo, você precisa ser um adulto portador de hepatite crônica $\mathrm{C}$ e preencher todas as características exigidas pelo protocolo. 0 seu médico irá avaliar se você tem essas características, e após a explicação de todos os procedimentos, você poderá decidir se quer ou não participar.

Caso você deseje participar do estudo, uma amostra de seu sangue será coletada para que alguns exames relativos à sua infecção pelo vírus da hepatite $\mathrm{C}$ sejam realizados.0 convite para sua participação nesse estudo será realizado durante consulta de rotina com seu médico e a coleta de sangue(caso você concorde em participar) será realizada durante a coleta dos exames de rotina que seu médico costuma solicitar, sem que essa coleta adicional represente qualquer trabalho adicional ou gasto extra (relativo a transporte). Após a coleta de sangue, o material ficará estocado em freezer no CRT Santa Cruz, até ser transportado para o laboratório onde os exames serão realizados. Nenhum exame adicional além dos previstos nesse estudo será realizado caso haja qualquer "sobra" do material coletado.

Esses exames são para se conhecer o tipo de vírus C que você carrega. Ou seja, será realizado exame para se tentar verificar, se o vírus da hepatite $\mathrm{C}$ que você tem, apresenta mutações que determinam resistência aos medicamentos usados para 0 tratamento da hepatite $\mathrm{C}$. 
Esses exames não são realizados de forma rotineira no tratamento de pessoas com seu problema. Os riscos envolvidos na coleta de sangue são: hematoma no local da punção e dor. Sua participação no estudo é voluntária.

Caso você não deseje participar do estudo, não haverá qualquer modificação no seu atendimento médico no Centro Referência Tratamento - CRT Santa Cruz, São PauloSP.

\section{Benefícios}

As informações obtidas através desse estudo são importantes para o seu atendimento médico e também você poderá estar ajudando futuros pacientes pela possibilidade de proporcionar informações importantes para o seguimento e tratamento da hepatite C crônica. Não está prevista qualquer forma de pagamento para sua participação nesse estudo.

\section{Desconforto e Riscos}

Coleta de Sangue: A coleta de sangue será realizada durante a coleta de exames de rotina, solicitados por seu médico. A coleta de sangue é levemente dolorosa e pode causar hematomas e, muito raramente, desmaio, coágulos sangüíneos ou uma infecção no local da injeção. Caso haja qualquer complicação decorrente da coleta de sangue, você será atendido por médico da equipe responsável pelo estudo e se necessário será encaminhado para complementação de tratamento (inclusive internação, se necessária) no CRT Santa Cruz. A equipe do CRT Santa Cruz será responsável por seu atendimento médico, não havendo nenhuma indenização especial prevista para a eventualidade de qualquer complicação decorrente desse procedimento.

\section{Alternativas}

Não há nenhum outro meio de obtermos as informações que desejamos além das medidas que esse estudo propõe.

IV - ESCLARECIMENTOS DADOS SOBRE GARANTIAS DO SUJEITO DA 


\section{PESQUISA:}

1. Você terá garantia, a qualquer tempo, que receberá as informações sobre procedimentos, riscos e benefícios relacionados à pesquisa, inclusive para esclarecimentos de qualquer dúvida.

2. Sua participação neste estudo é completamente voluntária. Você pode recusar a participar do estudo ou poderá descontinuar sua participação do mesmo, a qualquer momento, sem qualquer penalidade ou perda dos benefícios aos quais de outra forma faria jus. A Dra. Maria Cássia Corrêa irá prontamente aconselhá-lo sobre suas dúvidas. Se você decidir interromper sua participação no estudo, você deverá entrar em contato com 0 as pessoas responsáveis pelo estudo no telefone (11) 44946900 , de forma a permitir que os procedimentos de finalização de sua participação no estudo possam ser iniciados.

3. Haverá consulta de todos os dados relativos á sua história médica, que constam em seu prontuário, durante a realização desse estudo. No entanto, sua participação neste estudo será mantida em caráter confidencial e seu nome não será revelado a ninguém que não seja do estudo. Autoridades governamentais nacionais responsáveis pela segurança e conduta ética dos estudos com seres humanos poderão revisar os registros do estudo, e os registros poderão ser submetidos à divulgação decorrente de outras ordens ou requisitos governamentais. Caso os resultados deste estudo sejam publicados na literatura médica, você não será identificado nominalmente, sendo sua confidencialidade garantida em todas as ocasiões. 0 comitê de ética poderá ter acesso direto ao seu prontuário médico para verificação dos procedimentos de finalização de sua participação no estudo possam ser iniciados.

4. Você compreende que a Dra. Maria Cássia Corrêa tem o direito de interromper sua participação neste estudo, caso você não siga as instruções do mesmo, ou se considerar que esta interrupção seria de maior benefício para você. Caso seja descoberta qualquer nova informação significante sobre sua doença enquanto este estudo estiver sendo desenvolvido, você será imediatamente informado e poderá decidir continuar ou interromper sua participação.

5. Caso você venha apresentar indicação de internação hospitalar por qualquer 
motivo relacionado a esse estudo, ela será feita preferencialmente via CRT Santa Cruz, São Paulo - SP.

\section{INFORMAÇỐES DE NOMES, ENDEREÇOS E TELEFONES DOS RESPONSÁVEIS PELO ACOMPANHAMENTO DA PESQUISA.}

Você será incentivado a fazer perguntas, em qualquer ocasião durante o estudo. Caso você tenha perguntas sobre o estudo ou sobre seus direitos como paciente, por. faxor entre em contato com a Dra. Maria Cássia Jacintho M. Corrêa, no telefone (11) 4494-6900.

\section{OBSERVAÇÕES COMPLEMENTARES:}

NENHUMA

\section{CONSENTIMENTO PÓS-ESCLARECIDO:}

Eu li este Termo de Consentimento Livre e esclarecido e tive a oportunidade de discuti-lo com um dos membros da pesquisa. Todas as minhas perguntas foram respondidas. Eu fui informado sobre os riscos e benefícios e concordo de livre e espontânea vontade em participar deste estudo.

Eu entendo que posso sair do estudo a qualquer momento e que isso não afetará meu tratamento futuro.

São Paulo, de de

Assinatura do paciente ou seu representante legal

Data 1

Assinatura do Investigador que obteve o Consentimento, sob carimb.

Data 1 